\title{
ONGs, indios y petróleo: El caso U'wa a través de los mapas del territorio en disputa
}

ONGs, indiens et pétrole : le dossier U'wa à travers les cartes de la querelle territoriale

NGOs, indians and petroleum: the U'wa file through the maps of the land in dispute

\section{Margarita Serje}

\section{OpenEdition}

\section{Journals}

Edición electrónica

URL: http://journals.openedition.org/bifea/6398

DOI: $10.4000 /$ bifea.6398

ISSN: 2076-5827

\section{Editor}

Institut Français d'Études Andines

\section{Edición impresa}

Fecha de publicación: 1 abril 2003

Paginación: 101-131

ISSN: 0303-7495

\section{Referencia electrónica}

Margarita Serje, «ONGs, indios y petróleo: El caso U'wa a través de los mapas del territorio en disputa », Bulletin de l'Institut français d'études andines [En línea], 32 (1) | 2003, Publicado el 08 abril 2003, consultado el 08 diciembre 2020. URL : http://journals.openedition.org/bifea/6398 ; DOI : https://doi.org/10.4000/bifea.6398

\section{(c) $(1) \odot$}

Les contenus du Bulletin de l'Institut français d'études andines sont mis à disposition selon les termes de la licence Creative Commons Attribution - Pas d'Utilisation Commerciale - Pas de Modification 4.0 International. 


\title{
ONGs, INDIOS Y PETRÓLEO: EL CASO U'WA A TRAVÉS DE LOS MAPAS DEL TERRITORIO EN DISPUTA
}

\author{
Margarita SERJE*
}

\section{Resumen}

El presente artículo hace un análisis del caso U'wa, una confrontación que debe su celebridad a la amenaza de suicidio de un pueblo indígena frente a un proyecto petrolero adelantado por dos grandes compañías (la OXY y la SHELL) asociadas con el Estado colombiano. El relato de una "tribu" dispuesta a suicidarse a nombre de lo que ella considera sagrado ha llamado la atención no sólo de los medios en el mundo, sino de numerosas organizaciones no gubernamentales ambientalistas e indigenistas, las que han intervenido de manera activa en esta disputa que se desarrolla en medio del conflicto armado colombiano. El propósito de este artículo es el de adelantar una reflexión sobre el conjunto de relatos, imágenes y representaciones que han guiado las prácticas de los diferentes actores en la confrontación.

Todas las partes han preparado e incluso publicado mapas en algún punto de la controversia con el fin de sustentar, resaltar e ilustrar su argumentación. Todos ellos muestran el mismo conjunto de zonas: las del área de explotación petrolera y los territorios indígenas tanto reconocidos por la ley como los reclamados por los indígenas. Cada uno muestra, sin embargo, estas zonas y la relación entre ellas de manera particular y pone en relieve ciertos elementos. Estos mapas se pueden considerar como verdaderos textos culturales y constituyen así un corpus para aproximarnos a la confrontación. Debido a la pretensión de objetividad con la que se expresa la cartografía, los mapas aparecen ajenos a las posiciones que cada uno de los actores ha tomado en la discusión, y nos ofrecen por ello una ventana privilegiada para entrever las hipótesis y los supuestos de los que parten los diferentes actores.

Este trabajo nos aproxima, a través de los mapas, al "sub-texto" de los antagonistas, a las nociones, opiniones e intenciones que los actores no expresan explícitamente, es decir al "inconsciente político" detrás de cada línea de argumentación. A partir del análisis de la cartografía se concluye, por una parte, que la "agenda" que defiende el ambientalismo e incluso el indigenismo, tiene mucho más en común con la del desarrollo petrolero de lo que aparenta; y por otra, que los mecanismos a través de los cuales se esencializa la cosmología indígena, logran deslegitimarla e invisibilizarla de maneras paradójicas.

Palabras claves: Cartografía, etnicidad, indigenismo, petróleo, resolución de conflictos, ambientalismo.

* École des Hautes Études en Sciences Sociales 54, bd Raspail 75006 - Paris, France. E-mail: m.serje@ libertysurf.fr 


\title{
ONGs, INDIENS ET PÉTROLE : LE DOSSIER U'WA À TRAVERS LES CARTES DE LA QUERELLE TERRITORIALE
}

\section{Résumé}

Cet article explore les cartes du dossier U'wa. Cette confrontation est devenue célèbre suite à la menace de suicide d'un peuple indigène face à un projet pétrolier mené par deux grandes entreprises multinationales, OXY et SHELL, associées à l'État colombien. Le récit d'une " tribu " décidée à se suicider au nom de ce qu'elle considère sacré a attiré l'attention des médias du monde entier mais aussi de nombreuses organisations non gouvernementales (ONGs) écologiques et des droits de l'homme. Ces dernières ont une participation active dans cette dispute qui se déroule dans le cadre du conflit armé colombien. L'objet de cet article est de mener une réflexion à propos des récits, des images et des représentations avec lesquelles les différents acteurs agissent dans la confrontation.

À un certain moment de la controverse, toutes les parties ont préparé et même publié des cartes pour soutenir, souligner et illustrer leur argumentation. Elles montrent toutes le même ensemble de zones : celle de l'aire d'exploitation pétrolière et celles de la réserve indigène légalement reconnue et de l'aire réclamée comme territoire ancestral par les U'wa. Cependant chacun a choisi de montrer la relation entre ces surfaces de façon particulière et met en relief certains éléments. Ces cartes peuvent donc être considérées comme des textes culturels et conforment ainsi un corpus à explorer pour comprendre le conflit. Étant donné que la cartographie prétend être objective, les cartes sont apparemment éloignées des positions qui sont prises dans la discussion. Elles nous offrent, en conséquence, un point de vue privilégié pour entrevoir les hypothèses et les présuppositions de chacun des acteurs.

Cet article nous permet une meilleure approcheà travers les cartes, du " sous-texte " des antagonistes, des notions, opinions et intentions que les acteurs n'expriment pas de façon explicite, c'est-à-dire de l'inconscient politique de chaque ligne d'argumentation. L'analyse critique de la cartographie nous montre comment, paradoxalement, l' " agenda " des ONGs écologiques ressemble à celle des agents du développement pétrolier en s'appuyant sur le même type de catégories et de notions. Il nous montre aussi les dispositifs à travers lesquels la cosmologie indigène est rendue statique et essentielle, devenant en même temps invisible et sans légitimité.

Mots clés : Cartographie, ethnicité, indigénisme, pétrole, résolution des conflits, développement durable.

\section{NGOs, INDIANS AND PETROLEUM: THE U'WA FILE THROUGH THE MAPS OF THE LAND IN DISPUTE}

\begin{abstract}
This paper examines the U'wa affair, a confrontation that became well know when a small indigenous group threatened to commit collective suicide in response to an oil exploitation project by two transnational companies (OXY and SHELL) associated with the state in Colombia. The story of a "tribe" willing to commit suicide in the name of what they consider to be sacred not only attracted the attention of the media all over the world, but the activism of numerous NGO's devoted to the environment and human rights. These organizations have played a key part in this confrontation which took place in the midst of the Colombian armed conflict. This article reflects on the set of images and representations which has guided the experience and the practice of the actors in dispute.
\end{abstract}

At some point, all parties involved have prepared and even published maps intended to illustrate and sustain their argumentation. These maps all show the same combination of zones: those of the oil exploitation area and the indigenous lands, both the ones recognized by the state and the ancestral territories they claim as theirs. Each map shows these areas and the relation 
between them, but emphasizing particular features in different ways. They may thus be considered as cultural texts and constitute a corpus of information to approach and understand the conflict. Since cartography represents its objects in an allegedly objective manner, maps appear to be neutral in relation to the positions asserted by every actor. As a consequence, they offer a privileged standpoint from which to identify the hypotheses and assumptions that underlie their actions and enunciations.

The paper explores, trough maps, and the "sub-text" in the arguments put forth by each of the antagonists: the notions, opinions and intentions they are not express explicitly (i.e., the "political unconscious" of the argumentation). The critical analysis of the conflict's cartography shows how much the agenda of the environmental and human rights NGO's resembles that of the oil boosters, and the means through which the indigenous cosmology is construed as static and essentialist, and in this way, rendered invisible and illegitimate in paradoxical ways.

Key words: Cartography, ethnicity, indigenism, oil, conflict resolution, environmentalism.

\section{LA “PUESTA EN ESCENA” DEL CASO U'WA}

\section{1. Escena 1: la Consulta}

Cerca del mediodía del 10 de enero de 1995 en la ciudad de Arauca, situada en los llanos de la Orinoquia colombiana, se da inicio a una escena que en los últimos tiempos se ha vuelto cotidiana en Colombia: una reunión entre funcionarios representantes del Estado y "la comunidad". La que se lleva a cabo en esta ocasión tiene como participantes a funcionarios venidos de Bogotá: están presentes la directora general de asuntos indígenas y sus asesores cercanos, así como miembros del Ministerio del Ambiente, Ecopetrol, la empresa colombiana de petróleos y el Ministerio de Minas y Energía. A su lado, los representantes de una gran empresa petrolera que opera en Colombia, la Occidental Petroleum Corporation, conocida como OXY. La "comunidad" objeto de la reunión, la constituyen indígenas $U^{\prime} w a$, quienes habitan lejos de allí, en las faldas de la cordillera de los Andes. En el acta, aparecen como "representantes legales" de dicho pueblo varios "werjayas" o "Autoridades Tradicionales" y algunos miembros del Cabildo Mayor. Están también presentes cinco profesores, tres promotores, cinco estudiantes, nueve "miembros activos" y catorce "asistentes", en total 44 indígenas (1).

Como es usual en este tipo de eventos, seguramente los funcionarios del Estado y de las petroleras se sientan en un estrado alto, al frente, al lado de un tablero o de una cartelera. La reunión se inicia con el anuncio de que la moderación estará a cargo de la directora de los Asuntos Indígenas. Las "palabras de bienvenida" son pronunciadas por el director de "relaciones con la comunidad" de la empresa petrolera, quien se presenta así como anfitrión de la reunión. Se prosigue, como es común en este tipo de rituales, con la lectura del "orden del día" donde se enumera la secuencia de "intervenciones". Se informa que se trata de una "Consulta Previa", prevista por la Ley. Se aclara que es una reunión de "información y consulta” y que la secretaría de la misma la asumen

(1) La reconstrucción de la consulta se hace en base al "Acta de la Reunión de Información y Consulta Previa", Dirección General de Asuntos Indígenas, Ministerio del Interior, 11 de enero de 1995. 
los representantes del Estado. También se anuncia que se hará una traducción a los dos dialectos de la lengua "Uwa".

Para "hacer participación" se cuenta con toda una serie de prácticas, casi ya tradicionales, a través de las cuales el Estado ha venido construyendo una relación con las Comunidades. Se trata de prácticas que incluyen tanto la manera de convocar (por carta, por radio, a través de las organizaciones cívicas, de las juntas de acción comunal), como las formas particulares de reunirse. Se adopta una lógica y una forma escolarizadas en la que domina la escena una "mesa directiva" donde se sienten los funcionarios públicos y demás representantes del Estado, y enfrente el público que se acomoda a la manera de los alumnos en una clase o de los feligreses en una iglesia. Esta misma lógica escolar y disciplinaria es la que se impone para llevar a cabo la reunión: con el silencio de todos los presentes, en medio del sopor que produce el calor de medio día en el llano, se da inicio a los discursos y las exposiciones del caso por parte de los funcionarios. Después de presentar la misión y las intenciones de las entidades que representan, se hace una exposición sobre "el derecho indígena a participar en las decisiones que les afecten", citando leyes y decretos. Seguidamente se exponen la "política de hidrocarburos" del gobierno nacional y los términos del contrato firmado por el Estado con la Oxy para la exploración y explotación de petróleo, así como las características del proyecto en cuestión: sus objetivos y las consideraciones económicas, socioculturales, ambientales. Todo ello expresado correctamente a través del lenguaje y del vocabulario técnico adecuado para planificar el desarrollo: se habla de problemática, de instancias y de espacios, de impacto, de necesidades, de racionalidad y de costo-beneficio.

El proyecto que se trae a "consulta" surge de un contrato que había sido celebrado a comienzos de los años noventa, a través de la compañía colombiana de petróleos, Ecopetrol, con un consorcio de dos empresas multinacionales, la OXY y la SHELL, para explorar y explotar un área que en la cartografía fue denominada como Bloque Samoré. Este "bloque" o zona de potencial petrolero abarca una franja casi ortogonal de 209000 hectáreas en las faldas y el piedemonte llanero de la cordillera oriental, en la región conocida como Las Selvas del Sarare, que se expande hacia los Llanos Orientales en la Orinoquía colombiana. El área está irrigada por los numerosos ríos que bajan de la cordillera, que en esta esquina conforma un nudo conocido como la Sierra Nevada del Cocuy o de Güicán.

En su vertiente llanera, esta serranía se eleva casi desde el nivel del mar en las vegas del Arauca hasta alcanzar alturas superiores a los $5400 \mathrm{~m}$ en las cimas de sus picos nevados: el Güicán, el Ritacuva Blanco y el Ritacuva Negro. De sus alturas cubiertas con nieves perpetuas, desciende hacia el sur-occidente, hasta las estribaciones que confinan al norte el altiplano Cundi-Boyacense, una meseta casi continua que se despliega en el sentido Norte-Sur sobre la cordillera conformando una serie de planadas entre los 2400 y los $3100 \mathrm{~m}$, sobre las cuales, a cerca de $300 \mathrm{~km}$ al sur se ubica Santa Fe de Bogotá y más al norte, las ciudades de Tunja, Sogamoso y Duitama. Hacia el Oeste la serranía desciende abruptamente al fondo de los valles de los ríos Chicamocha y Suárez, donde se ubica un poco más al norte la ciudad de Bucaramanga. La cordillera se prolonga en dirección Noroeste hacia Mérida en Venezuela. 
La Serranía del Cocuy alberga entre los pliegues de su compleja topografía una gran diversidad de climas y de paisajes húmedos tropicales. Se encuentran allí zonas nivales y de páramos, valles glaciares, bosques andinos de alta montaña, selvas subandinas de niebla, selvas basales y bosques aluviales. La zona es un relicto de toda una variedad de bosques tropicales de montaña: uno de los paisajes con mayor riesgo de extinción en el planeta.

La región se caracteriza también por ser una zona de múltiples fronteras: entre la montaña y el llano, los Andes y la Orinoquia y entre Venezuela y Colombia. En la serranía la entrecruzan las líneas divisorias de cinco departamentos: los de Arauca, norte de Santander, Santander, Casanare y Boyacá. Pero sobretodo Las Selvas del Sarare constituyen lo que se puede considerar como una "frontera interna" en el territorio nacional colombiano. Una zona que por razones múltiples, que podrían ser objeto de otro trabajo, ha escapado históricamente al control del Estado.

La administración colonial ejerció su dominio en el altiplano cundi-boyacense abarcando débilmente la serranía alrededor de los poblados de Chita y de Güicán, pero no es sino en este siglo cuando los territorios del llano y el piedemonte entran en los círculos de acción nacionales y siempre de manera marginal. La presencia estatal casi que se vio limitada hasta los años sesenta a la presencia de Misiones, en las que el Estado delegó la civilización de sus territorios agrestes, y al apoyo esporádico a la colonización del Sarare. Para esto se llevó a cabo la construcción de algunas vías de penetración de carácter precario, como la vía que une Tame con Yopal y la carretera que va de Arauca a Pamplona, a lo largo de la cual se fundaron los pueblos de Saravena, Cubará, Tunebia y Samoré.

En la cordillera, los poblados de Güicán, Cocuy y Chiscas están unidos vialmente con el altiplano, pero se consideran pueblos remotos y de difícil acceso, marginales con relación a los circuitos de actividad del departamento de Boyacá. El Sarare ha sido siempre percibido como una zona de refugio y por ser escenario del conflicto armado entre las guerrillas y el ejercito, como "zona roja". Hace parte de una serie de regiones vistas como periféricas, habitadas por indios y colonos, nidos de guerrilla y narcotráfico, concebidas como "tierra de nadie" donde se impone la "ley de la selva".

Poblada actualmente por varios grupos sociales, la región comprendida por el "bloque Samoré" es una región desde el punto de vista social también diversa: habitan allí campesinos llaneros y campesinos-colonos provenientes de distintas partes del país que llegaron a poblar el piedemonte desde el Meta hacia el Arauca, desplazados por las múltiples violencias que han marcado la historia de Colombia, y, desde épocas pre-hispánicas, los U'wa o tunebos (como se les llamó en la colonia) quienes ocupan actualmente la vertiente nororiental de la sierra y cuyos representantes se sientan ese día entre los asistentes a la reunión de "información y consulta".

La firma del contrato entre Ecopetrol y las compañías petroleras casi coincide con la adopción en Colombia de una nueva Constitución en 1991. La nueva carta contrasta, sin duda, con la antigua que definía la nación sobre la base únicamente de la tradición hispana, católica y castellana. Reconoce y protege, según el artículo séptimo, "la diversidad étnica y cultural de la Nación colombiana". Otorga y fortalece los derechos de los pueblos indígenas y afroamericanos, para garantizar la protección efectiva de su 
"integridad social y cultural". De acuerdo con la constitución se ha previsto la realización de una "consulta previa" a las comunidades indígenas a propósito de cualquier proyecto de desarrollo o medida que pueda afectar su integridad social y cultural (2).

Es precisamente en el transcurso de esta "reunión de consulta" donde se plasman los argumentos que serán el meollo de la controversia que va a adquirir una enorme visibilidad en la vida pública colombiana y en el mundo del ambientalismo de ese día en adelante. Uno de los puntos centrales de la argumentación del Estado en el transcurso de la reunión es la definición misma de qué es una consulta (según lo consignado en el acta de la reunión):

Un delegado U'wa preguntó si la consulta era para decir si o no y [la directora de la DGAI] respondió que la consulta no es para decir si o no a un proyecto, sino para que la comunidad entienda cómo se puedan ver afectados por los trabajos que se van a realizar, estudiar cuáles serían las incidencias socioculturales del proyecto y formular soluciones, así como los beneficios a los que deba acceder la comunidad"... "No es un permiso de los indígenas sino una apreciación sobre afectaciones $[\mathrm{sic}]$ posibles de un proyecto a un pueblo indígena".

El Estado entiende como hecho incuestionable que la decisión sobre el desarrollo del proyecto petrolero está en sus manos. Desde su punto de vista el problema se reduce a identificar con los indígenas las medidas a tomar para ajustar su ejecución. Y finalmente, se sientan las bases para el inicio de un diálogo de sordos: los "Acuerdos" a los que se llega al final de la reunión son entendidos de maneras diferentes por las partes. Al entender del Estado, hay "unanimidad" para hacer algunas rectificaciones al proyecto sísmico en conjunto con los $U^{\prime} w a$, para lo cual se conformaría una comisión intercultural. Al entender de los representantes del pueblo $U^{\prime} w a$, se llegarían a acuerdos en una reunión posterior, después de haber reflexionado y consultado con los mayores y con las autoridades. Los indígenas entienden la propuesta que les hace el Estado como una trampa: la explotación del territorio a cambio de los "beneficios" del desarrollo; es decir de contaminación, vías de penetración, afluencia masiva de colonos, urbanización, invasión de sus territorios, deforestación, corrupción, militarización, extorsión, secuestro (Acta del Tercer Congreso U'wa, 7 de enero de 1995).

A lo largo de la controversia ha madurado y se ha consolidado un grupo de líderes: la Asociación de Cabildos y Autoridades Tradiciones -AsoU'wa - cuya figura principal es Berito, o Roberto Cobaría. Se trata de un grupo bilingüe, casi todos escolarizados en la misión del Chuscal. Hacen parte del treinta por ciento bilingüe de la población U'wa y del quince por ciento letrado (IDEADE, 1996). Por otra parte, se ha ido configurando una imagen, una representación del pueblo indígena en cuestión: han surgido los $U$ 'wa, con apóstrofe, en nombre de quienes se desarrolla la controversia

(2) El articulo 330 de la Constitución consagra el derecho de los pueblos indígenas a participar en las decisiones que se adopten respecto a la explotación de recursos naturales en sus territorios. En desarrollo de este precepto constitucional, el articulo 6 de la ley 99 de 1993 (conocida como Ley del Ambiente) estableció que las decisiones en torno a la explotación de los recursos naturales en los territorios indígenas se adoptarán previa consulta a los representantes de dichas comunidades. 
(3). Invisibles y ajenos, tras estos dos "personajes", cerca de cinco mil indígenas, enfrentan sus avatares, allá en las faldas nororientales de la Sierra Nevada del Cocuy.

Frente a los planes del Estado, se pone sobre la mesa de discusión una representación de la sociedad y del territorio $U$ 'wa que constituye un poderoso instrumento de negociación, central para sustentar toda una línea de argumentación. "Los $U$ 'wa" que encontramos en escena se han ido configurando a través del diálogo entre las varias instancias y retóricas: las asambleas y reuniones comunitarias, los planteamientos de los líderes y cabildos, las alegorías y metáforas con las que se expresan los mayores indígenas que han sido consultados, así como la retórica con que se expresan los medios, las interpretaciones y conceptos que aportan las organizaciones ambientales y los diferentes asesores que han participado activamente en el proceso. Esta representación dialoga con los argumentos y contra-argumentos de los otros actores involucrados en la controversia y es, a su vez, producto de este diálogo.

La tensión central alrededor de la cual se desarrolla esta representación de "La Cultura, La Ley y El Territorio U'wa”, es la de la oposición clásica entre lo tradicional y lo moderno. Los U'wa se sitúan como pueblo “tradicional”, un pueblo que ha mantenido un cierto estado de pureza, que prácticamente no ha sido contaminado por el contacto con la sociedad occidental. Aquí radica su autenticidad y de cierta manera su legitimidad. Se nos muestra como un pueblo que vive de acuerdo con tradiciones milenarias, que ha luchado por mantener las Leyes y Saberes originarios de sus ancestros, frente a la amenaza de la civilización. Se invoca constantemente "La Ley Sagrada", la que constituye a la vez una ley espiritual y un saber esotérico: "cosas que por tradición no debemos revelar al blanco: actos y pensamientos que desarrollamos en días de Baile, Canto, Ayuno y Trabajo" (4). Se expresan así las bases de una "cultura milenaria", en la que "pueblo y autoridades somos una misma familia", en la cual:

"Nosotros, el pueblo U'wa, somos y vivimos en un mundo diferente al del blanco. Tal vez no lo sea desde el punto de vista físico, del sol, la luna, las montañas y los ríos. Pero nuestra forma de entenderlo, concebirlo y estudiarlo si es diferente (...) Nosotros los U'wa concebimos el territorio como la esencia de la vida; tenemos una forma muy especial de controlar el medio ambiente, nuestro comportamiento con respecto a éste se explica en los mitos, creencias, usos y costumbres, cuya antigüedad es la misma del origen de nuestro mundo, de nuestra población y de nuestra cultura; nuestra misión en esta tierra ha sido la de mantener el equilibrio de origen" (U'wichita, 1996)

Se nos presenta el mundo U'wa como espiritual, en virtud de su adherencia a esta Ley atemporal, situada en un tiempo mítico, estática e inmutable, en la que se ratifican los valores de la comunidad originaria, colectiva, igualitaria. Esta Ley es el

(3) De acuerdo con Jon Landaburu, director del CCLA, Centro de Investigaciones Lingüísticas de la Universidad de los Andes, la ortografía adecuada sería sin apóstrofe: Uwa (Comunicación personal). El uso del apóstrofe, que tiene un obvio papel en la exotización de este pueblo, se ha generalizado en todas las expresiones públicas de este conflicto, por lo que he decidido adoptarlo para este trabajo.

(4) Tomado de "Uwichita”, documento presentado por Asou'wa en la "Audiencia U'wa por la vida", 20 de julio de 1996. 
sustento y la posibilidad del "saber tradicional" y las prácticas que "nos ha permitido por miles de años mantenernos en armonía con la naturaleza y con nosotros mismos" y "el equilibrio de origen". La idea del Territorio Ancestral de cierta manera sintetiza los aspectos centrales de la representación pública de la organización indígena Asou'wa, de su discurso estratégico: se trata de un territorio que, como la cultura en nombre de la cual se invoca, constituye una realidad única, coherente, monolítica con límites claramente definidos. Un territorio que puede ser definido en función de una serie de atributos materiales e ideales que le son esenciales: las tradiciones, los usos y costumbres, la espiritualidad, la ancestralidad, el comunitarismo, el ecologismo.

Con el encuentro de Arauca, el gobierno dio por cumplido el requerimiento de la participación comunitaria y antes de que se realizara esa segunda reunión prevista, el Ministerio del Ambiente expidió la licencia para iniciar el proyecto. Esto se le informa a los delegados indígenas en la siguiente reunión a la que los delegados del gobierno y las petroleras venían con el fin de hacer un listado de "lugares sagrados" para modificar el proyecto sísmico. Berito, o Roberto Cobaría, el vocero de los indígenas expresó que "para ellos todo el resguardo era sagrado, y que no podía establecer sitios específicos." (Acta de la reunión de Seguimiento a la Consulta con el pueblo U'wa, OXY, 27 de enero de 1955).

\section{2. Escena 2: el Suicidio}

Los representantes indígenas expresan públicamente que se oponen a la explotación petrolera, la que es para ellos sinónimo de etnocidio. Manifiestan que el Estado no ha tenido en cuenta su punto de vista y denuncian su constante negligencia para resolver la situación de los terrenos que la ley les reconoce hasta ese momento como resguardos, la que es mucho menor que el área ocupada por ellos efectivamente. Desde su punto de vista la Constitución Nacional establece claramente que no se deben llevar a cabo las iniciativas de desarrollo que los indígenas consideren como un atento contra su vida como sociedad y como cultura (5), y finalmente afirman que:

"Preferimos una muerte digna, propia del orgullo de nuestros antepasados que retaron el dominio de conquistadores y misioneros" (Manifiesto Público del Pueblo U'wa", junio de 1995)

Los medios exponen ampliamente el caso y en la prensa aparece, en abril de ese año, la noticia en primera plana: "Cinco mil indígenas amenazan con suicidarse" titula el díario El Nuevo Siglo el 28 de abril de 1995, invocando una vieja historia, la del "Peñón del orgullo Tunebo" o "Alto de los Infieles" o "de los Muertos": un alto en la serranía cerca de Chita desde donde, según se cuenta en la región, los Tunebos se lanzaron al vacío durante la colonia, prefiriendo esa muerte a la suerte de ser encomendados. Según se cuenta, miles de indígenas metieron a sus hijos en ollas de barro y los arrojaron al abismo, después de lo cual caminando hacia atrás, los adultos se dirigieron al borde y también se lanzaron. El cacique que había hablado el primero,

(5) Según entrevistas con José Cubará, Gloria Tegría y Roberto Cobaría, líderes de Asou’wa, en El Chuscal, 12.02.1998. 
fue el último en botarse. Su cuerpo coronó la montaña de cadáveres que reposaba en el fondo. Los que quedaron para ser testigos de lo acontecido cuentan que era tan grande el volumen de cuerpos apilados en el fondo del desfiladero, que el curso del río cambió desde entonces.

La amenaza del suicidio colectivo tiene importantes secuelas: moviliza la opinión pública nacional e interesa a la prensa internacional, a las organizaciones populares e indígenas, y a las ONGs ambientalistas y de derechos humanos. Por esos días el ELN, Ejército de Liberación Nacional, secuestró dos técnicos de la empresa contrastista de la OXY y días después, retuvo al Senador Indígena Lorenzo Muelas, quien se había desplazado a la zona para conocer de cerca la situación.

Una vez liberado, el senador se dirige al Ministerio del Ambiente para solicitar la revocatoria de la licencia al tiempo que de la Occidental inicia trabajos de exploración sísmica en el área externa a los límites de los resguardos reconocidos legalmente, pero dentro del área del resguardo único solicitado por los U’wa. En la prensa se comienzan a manifestar opiniones por parte de los altos funcionarios, tanto del Estado como de las empresas petroleras diciendo que los indígenas "padecen del poder de intimidación de la guerrilla" [sic] (El Tiempo, 02 de febrero de 1997, p. 11A) implicando que su oposición al desarrollo petrolero tiene origen en su adhesión a la guerrilla. Ecopetrol lanza entonces una campaña publicitaria con el lema "sin petróleo no hay vida", que pretende mostrar las ventajas del hidrocarburo alegando que sin éste seríamos verdaderos "hombres [sic] de las cavernas", recurriendo a viejos estereotipos coloniales que sustentan la posición que el Ministerio de Minas y Ecopetrol han hecho pública en repetidas oportunidades, la idea de que "no es posible que los intereses de tres mil U'wa se opongan a los intereses y al bien común de 35 millones de colombianos" (6).

\section{3. Escena 3: "Colombia es U'wa"}

En abril de 1995 la Occidental anunció públicamente que no iba a iniciar las actividades de exploración previstas en el Bloque Samoré hasta tanto no se encontrara una salida concertada con el pueblo U'wa. La comunicación entre las partes se ve, sin embargo, cada vez más deteriorada. Una coalición de ONGs colombianas conforman y lanzan un proyecto denominado "Colombia es U'wa". En abril de ese año, en Bogotá se realiza una marcha sin precedentes en un país donde ya ninguna muerte ni ninguna masacre provoca reacción. A la voz de la amenaza de suicidio se moviliza la ciudadanía frente al Ministerio del Ambiente. Las ciudades colombianas se ven inundadas con graffittis:

"Las culturas con principios no tienen precio"

"El territorio U'wa es sagrado"

"Sin ancestros, sin territorio, sin niños, sin amor, pero con petróleo"

"Detengan el etnOXYdio"

(6) Este argumento ha sido esgrimido más de una vez. Ver por ejemplo las declaraciones de Luis Carlos Valenzuela, Ministro de Energía en Semana (Bogotá) № 911 (18 de octubre de 1999). 
En agosto de 1996 el senador Muelas convoca una "Audiencia por la Vida" en San Luis del Chuscal, población sobre el río Cobaría, lugar de entrada al territorio U'wa y sede de un internado misional. En la "Audiencia Por la Vida" se reunieron organizaciones sociales de todo el país, movimientos ambientales, académicos, la prensa nacional e internacional y numerosas ONGs internacionales. El gobierno estuvo ausente. Allí, se hizo público “el comunicado del pueblo U’wa a todos aquellos sectores que aún consideran que la tierra es mujer y madre a quien debemos cuidar y respetar", documento donde se invocan las imágenes centrales que nutren la posición y la figura de "los U'wa" como personaje de esta confrontación. A través de los medios la imagen de una tribu ancestral dispuesta a un suicidio colectivo si la explotación petrolera avanza en su territorio, recorre el mundo.

\section{4. Escena 4: en la aldea global}

A finales del año de 1996, desde Washington, The Coalition for Amazonian Peoples and their Environment lanza una "acción de alerta" por Internet con relación al caso U'wa. Un año después una coalición de ONGs en los Estados Unidos crea un grupo de trabajo para la defensa de los U'wa: el U'wa Defense Working Group (UDWG) (7). El grupo basa su campaña en una manera muy particular de ver a los U'was. Surge, sin duda, de la representación construida por Asou'wa pero se alimenta también de la imagen dominante del indio en los Estados Unidos: el noble, bello y orgulloso héroe, sobreviviente de una historia de luchas, miembro de una "tribu" en vía de desaparición (Clifford, 1976; Ellingson, 2001). La imagen de los U'wa que presentan, se centra en dos relatos: el del suicidio y el de la utopía ecológica; se hace énfasis en el misticismo, el chamanismo, la cura espiritual, las medicinas y saberes tradicionales. Un ideal que evoca todo aquello que los ambientalistas quisieran que fuera sagrado, respetado y, sobre todo, que fuera coherente.

En abril de 1997, el presidente de la OXY se dirige directamente a Berito Cobaría, expresando por carta la voluntad de la compañía para entrar en diálogo. Por esos mismos días, él mismo, en declaraciones para El Tiempo, diario de mayor circulación en Colombia, afirma que el territorio U'wa es "la casa del cura Pérez" ( $E l$ Tiempo, 21 de abril de 1997). El cura en cuestión era entonces el comandante del ELN, grupo guerrillero que se ha reivindicado los cerca de 500 bombardeos al oleoducto de Caño Limón y que ha venido en los años anteriores secuestrando y "boleteando" a las firmas contratistas de la OXY en la zona. Con el ánimo de protegerse frente a la amenaza guerrillera, las compañías petroleras tienen un convenio de cooperación para la seguridad de las instalaciones con el Estado colombiano, mediante el cual aportan recursos para que el ejército militarice las instalaciones. En 1997 se contaba, según declaraciones del presidente de la OXY con "cerca de 200 hombres del ejército y 90 de la policía. En octubre se crearon dos unidades de contraguerrilla nuevas en el área,

(7) Incluye a: Action Resource Center, Amazon Watch, Centerfor Justice and International Law, Earth Justice Legal Defense Group, Earth Trust Fund, Rainforest Action Network, Sol Communications y Project Underground. Esta última ha abierto un página web: U'wa in Crisis, <http://www.uwa. moles.org>; <http://arcweb.org-campaings/uwa>. 
la asociación SHELL-OXY va a aportar este año 13 millones de dólares (...) en general el diez por ciento de los costos operacionales son para seguridad y eso es el porcentaje más alto de cualquier país en el mundo" (El Tiempo, 21 de abril de 1997). Por otra parte hay que contar el Impuesto de Guerra, "en total OXY pagará este año más de treinta millones de dólares en concepto de seguridad". La presencia de las Fuerzas Armadas Nacionales en la región se ve entonces claramente identificada con la de las compañías petroleras y se percibe, por lo tanto, asociadas a sus intereses.

Las afirmaciones públicas que señalan la organización indígena como objeto de la influencia guerrillera se convierten prácticamente en una sentencia de muerte. Efectivamente, un par de meses más tarde Berito Cobaría es golpeado brutalmente y amenazado de muerte por hombres encapuchados.

La acción de las ONGs ambientalistas norteamericanas se intensifica. En abril de 1998, le otorgan a los U'wa, dos prestigiosos reconocimientos a su "gestión ambiental": el premio Bartolomé de Las Casas entregado por el Príncipe de Asturias y el Premio Goldman, considerado como el "Nobel del Ambiente". La visibilidad internacional indudablemente ha fortalecido como interlocutores a los representantes U'wa. Las empresas petroleras son sensibles a este tipo de escándalo y para el Estado colombiano es crucial resolver su responsabilidad en cuanto a situaciones de violación de los derechos humanos, uno de los temas candentes de su agenda internacional, en particular para obtener la "certificación económica" de los Estados Unidos y el acceso a la "cooperación internacional".

El caso U'wa había sido discutido en los dos altos tribunales colombianos: el Consejo de Estado y la Corte Constitucional, cuyas sentencias, a pesar de haber sido percibidas como contradictorias, presentaban diferencias de matiz(Sousa Santos \& García, 2001: capítulos XIII yXIV).Amediados del año, conjuntamentela ONIC,AsoU'way Amazon Coalition presentan una demanda ante la Corte Interamericana de Derechos Humanos — IACHR — alegando la violación de los derechos fundamentales del puebloU'wa.El gobierno, buscandohacerle frente a la presión externa, en particular ahora que se presenta en forma de demanda por violación a los derechos humanos, decide convocar a la OEA para que intervenga facilitando una salida negociada al conflicto. Se constituye para ello una comisión conformada por la Unidad para la Promoción de la Democracia de la OEA y el "Programa para la Resolución Pacífica y la Supervivencia Cultural”, adscrito al Centro Weatherhead de Estudios Internacionales de la Universidad de Harvard. Durante la segunda mitad de este año, separadamente, las comisiones de la Corte Interamericana y la Comisión OEA-Harvard desarrollan sus indagatorias. Para ello se reúnen con los principales protagonistas. Ninguna de las dos comisiones logra sin embargo desplazarse al "campo", es decir recorrer alguna porción del "territorio Uwa", pues el difícil acceso y la "situación de orden público" lo impiden (8). A finales del año la comisión OEA-Harvard presenta un documento con sus recomendaciones, las que se centran en la necesidad de adelantar un diálogo entre las partes y propone un programa de entendimiento intercultural y el reconocimiento por parte del Estado del resguardo único. Por su parte la IACHR hace a las partes la proposición de adelantar un proceso para resolver amistosamente el conflicto. La proposición fue aceptada por las dos partes.

(8) Según comunicación personal con Theodore Mc Donald, miembro de la comisión OEAHarvard en Cambridge, Mass. 30 de enero de 1998. 


\section{5. Escena 5: en el ojo del conflicto armado}

El optimismo que introduce la elección, en agosto de 1998, de un nuevo gobierno que nombra a un conocido ambientalista e indigenista al frente del Ministerio del Ambiente, se ve de repente dislocado por el anuncio de las FARC de declaratoria de guerra al oleoducto Caño Limón-Coveñas y a las petroleras en la región (El Tiempo, 22 de junio de 1999). La guerra contra la política y la explotación petrolera había sido adelantada hasta ese momento casi exclusivamente por el ELN.

En agosto del mismo año, las organizaciones campesinas del Sarare llevaron a cabo un paro de casi quince días. La región del Sarare tiene una tradición de movilizaciones campesinas a partir del vacío que dejaron los proyectos de colonización dirigidos por el Estado en la región. Estos se iniciaron en 1943 con el "Proyecto de la Colonia Agrícola y Ganadera del Sarare" que recibió dos empujones, el primero en 1959 por parte de la Caja Agraria y el segundo en 1965 por parte del Incora con el llamado proyecto Arauca I (Rucinque, 1972). Estos proyectos crearon y alimentaron una serie de expectativas en los campesinos que nunca se vieron realizadas, como la construcción de vías, la posibilidad de comercializar los productos, el acompañamiento técnico, el acceso a servicios básicos. Ello se ha expresado en la secuencia de movilizaciones cuyos argumentos no han variado sustancialmente desde el paro del Sarare de 1972 (Castro Caicedo, 20 de febrero de 1972; 22 de febrero de 1972). En 1998, sin embargo uno de los puntos centrales de la movilización fue la solidarización con la causa U'wa, en virtud de las "consecuencias económicas lamentables [de la explotación petrolera] para la región, que generó corrupción, problemas de orden ecológico (...) e incrementó la violencia...", según declaración de uno de los líderes a la prensa (Sarare: tres décadas de olvido, El Tiempo, 12 de agosto de 1998).

La reacción militar a la ofensiva guerrillera y la paramilitar a la movilización campesina no se hicieron esperar (El Tiempo, 15 de diciembre de 1998; 22 de diciembre de 1998; 3 de enero del 2001). En medio de este escenario, a comienzos de 1999, tres activistas norteamericanos del Uwa Defense Project, fueron secuestrados y asesinados a manos de las FARC, cuando se desplazaban al terreno para trabajar en su asesoría a los indígenas. Mientras tanto, el nuevo gobierno adelanta las gestiones para la definición del "Resguardo Unido U'wa", el que es entregado en agosto de 1999 (9) simultáneamente con la expedición de la autorización para iniciar la explotación petrolera en el sitio de Gibraltar, punto ubicado a tan sólo $5 \mathrm{~km}$ de la línea que marca el límite del nuevo resguardo.

\section{LA CARTOGRAFÍA DEL CASO U'WA}

Una de las cosas que impacta al ir leyendo toda la serie de documentos públicos que se han producido en el marco de la confrontación, es encontrar que entre la maraña de la retórica con la que se expresan las partes (que podría ser objeto de otro trabajo), se destaca la simplicidad de los mapas con los que cada cual acompaña e ilustra su discurso. ¿Cómo es posible que, en medio de una argumentación tan enredada, los mapas que parecen resumir para cada cual el centro de la tormenta, sean algo tan

(9) Resolución 056 del 6 deagosto de 1999. 
parco, tan llano, tan simple? Este hecho acaparó mi atención y terminé por concluir que esta aparente simplicidad, puede ser una clave importante para entender la forma en que cada actor "lee" la situación. Me pareció clave porque una simplificación de tal magnitud, implica tomar decisiones drásticas sobre lo que se toma y lo que no se toma en cuenta. A través de ella es posible por lo tanto, acercarnos a la "agenda oculta" de cada una de las partes, es decir a las nociones, opiniones y propósitos que los distintos actores no manifiestan explícitamente.

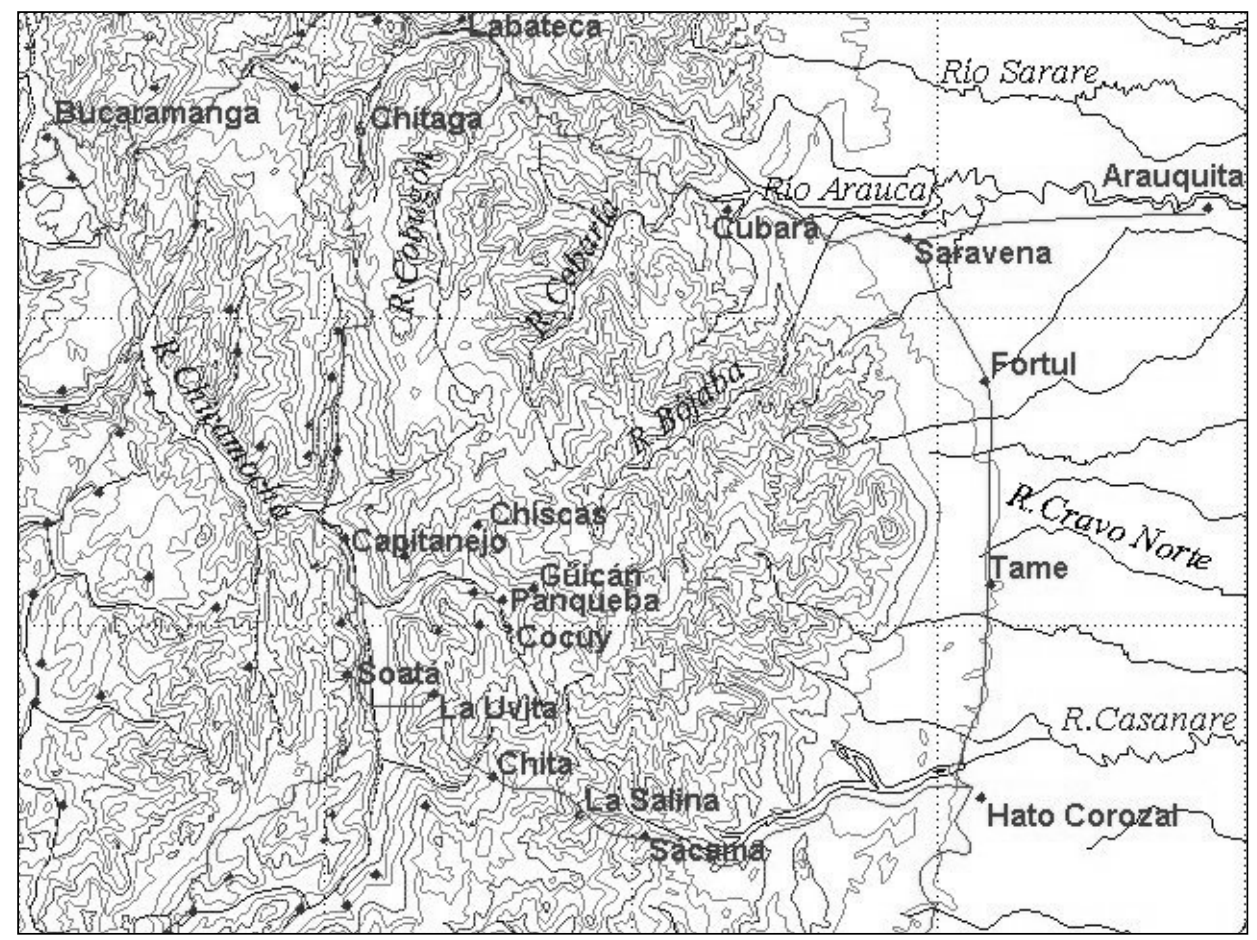

Fig. 1 - Mapa de la región elaborado por el autor.

\section{1. "El Mapa engendra el Territorio"}

No es novedosa la noción de que los mapas no tienen únicamente como fin el de realizar una descripción topográfica, sino que se elaboran, pensando en sus lectores o usuarios potenciales, de acuerdo con propósitos claramente políticos. Borges cuenta en su Historia Universal de la Infamia, el relato del prodigioso mapa de un Imperio, tan preciso y completo que sus dimensiones coincidían punto por punto con las del Imperio. Por su total infructuosidad terminó por ser abandonado a los rigores del sol y de las lluvias. La utilidad de un mapa no está en la exactitud de lo que representa, sino en la representación misma. El poder de la cartografía occidental radica en que, al situarse bajo la sombrilla de la ciencia, produce representaciones del mundo que pretenden ser precisas, neutrales y objetivas. Su supuesta neutralidad niega el orden social que representa, al tiempo que lo legitima. Los mapas, como cualquier otra imagen 
históricamente construida presentan, como lo señala Mitchell (1986: 8): "una apariencia engañosa de naturalidad y transparencia, detrás de la cual se oculta un mecanismo de representación arbitrario, distorsionante y opaco, un proceso de mistificación ideológica". Lo que Harley (1989: 2) llama "el inconsciente político del mapa".

El poder de los mapas se ejerce directamente sobre el conocimiento que hacen accesible. Más que describir el mundo, a través de sus formas convencionales y convencionalizadas, le imponen una estructura y una visión restringida. Mapear es un ejercicio selectivo. El mapa nos muestra, no lo que ve quien lo hizo, sino lo que se quiere que veamos. Su estructura simplificada se usa para organizar y hacer legible la intrincada realidad, de manera que esta termina por ser percibida a través de los "lentes", del filtro que propone el mapa. Para ponerlo en palabras de Monmonier (1993: 23) "No solamente es fácil mentir con los mapas, sino que es esencial hacerlo. Para poder reproducir de manera significativa sobre una hoja de papel (...) las complejas relaciones de un mundo tridimensional, el mapa debe deformar la realidad. El mapa nos muestra una visión de la realidad necesariamente selectiva e incompleta ...". Hay por lo tanto, una relación directa entre el uso para el cual fue elaborado el mapa, los supuestos con los que se elabora, los usuarios o lectores a los que se dirige y la forma gráfica que este asume para satisfacer todos estos criterios. Por ello, a pesar de que el mapa no es el territorio, al mostrarlo, al traerlo a la luz, logra crearlo de nuevas maneras. El mapa termina así, por engendrar el territorio.

La finalidad de los mapas es, en últimas, la de hacer posible una realidad que va a ser "consumida" o transformada de una cierta forma. Scott (1998: 21) señala cómo los mapas catastrales del Estado no describen meramente una estructura de tenencia de la tierra, sino que la crean como sistema. Lo logran al "desmembrar todo un conjunto de relaciones excepcionalmente complejas y muy pobremente comprendidas, para poder aislar un solo elemento de valor instrumental" . Este proceso de abstracción y simplificación está gobernado por un número reducido de objetivos, uno de los cuales es el de crear la uniformidad necesaria para hacer "legible" la realidad y poder así proceder a manipularla.

Los mapas están diseñados para resumir precisamente los aspectos del mundo que son del interés inmediato del autor, ignorando el resto. Son, ante todo, instrumentos diseñados con el propósito de que una cierta lógica prevalezca. Se construyen de la misma manera que las "inscripciones”, concepto con el que Latour \& Woolgar (1988) designan el proceso mediante el cual, durante producción del conocimiento científico, los hechos materiales se ven transformados por los investigadores en los postulados, figuras o diagramas necesarios para sustentar su argumentación y demostrar la validez de sus interpretaciones. Se constituyen así en objetos particulares con historias específicas.

\section{2. Los Mapas de la Controversia}

Todos los actores han preparado mapas en algún punto de la controversia. Aquí me voy a centrar en el análisis de los mapas que han sido publicados por las partes para acompañar, enfatizar e ilustrar su argumentación. Todos ellos muestran un mismo conjunto de áreas: la del "Bloque Samoré", las del resguardo y la reserva indígenas legalmente reconocidas y las de los parques naturales. Todas las ubican en relación con la frontera con Venezuela. Sin embargo cada uno ha escogido mostrar un ámbito geográfico distinto, a la vez que cada uno muestra la relación entre estas áreas de manera particular y ha preferido destacar diferentes elementos. 


\section{2. 1. Mapa "Bloque de Samoré - Territorios Ancestrales"}

Este Mapa fue preparado por OXY en 1993 y se ha convertido en la referencia que se utiliza por parte del Estado. Aparece en las carteleras en las reuniones oficiales institucionales y como anexo de muchos de los documentos institucionales (10). Ha

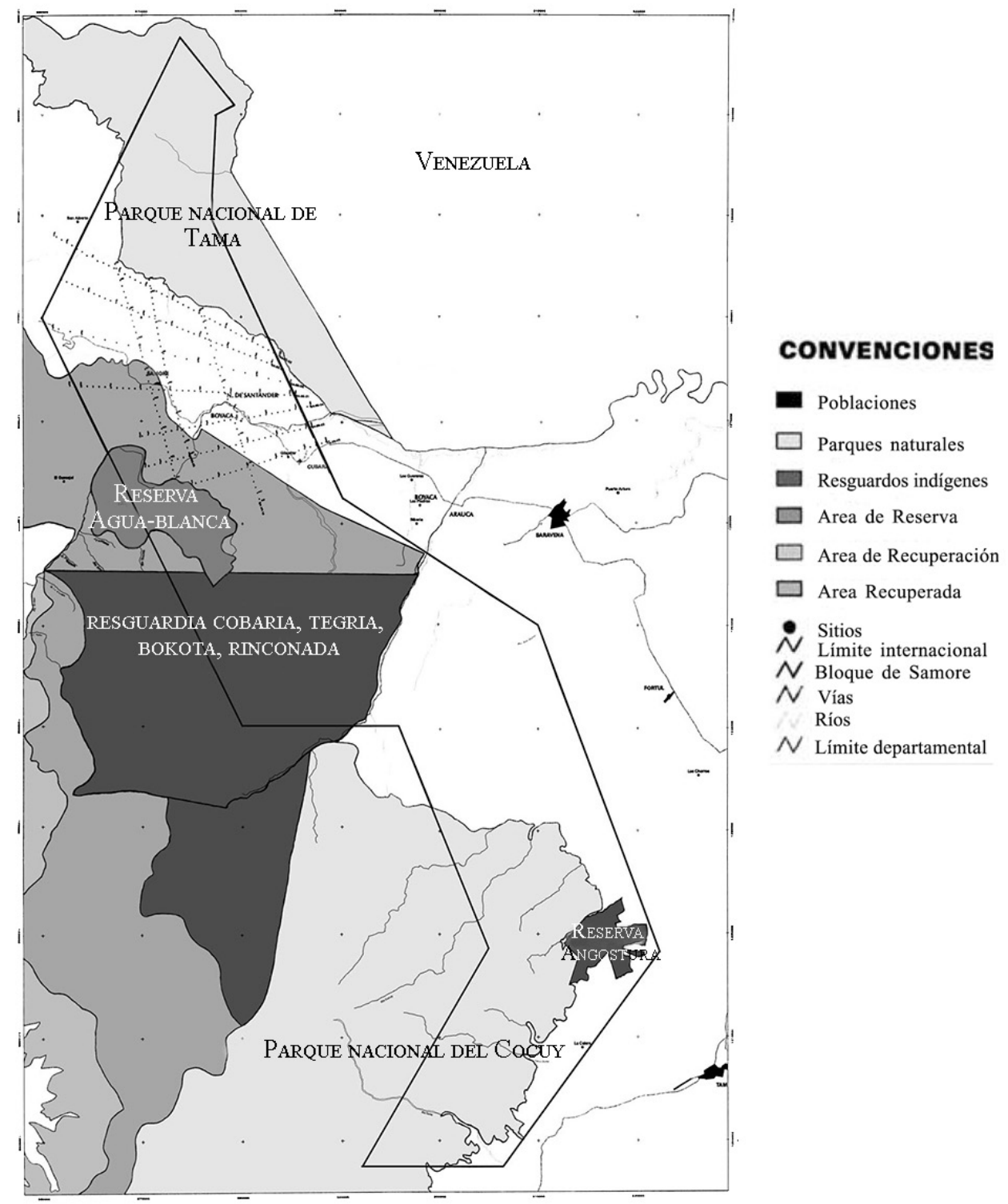

Fig. 2 - "Bloque de Samoré y Territorios Ancestrales".

(10) Ver por ejemplo el Informe a la División de Asuntos Especiales del Ministerio de Relaciones Exteriores, presentado por el Comité Interinstitucional para el caso Uwa en abril de 1998. 
sido reproducido ampliamente por la prensa varias veces (El Espectador, 10 de abril del 2000; El Tiempo, 26 de mayo de 1998; El Tiempo, 22 de setiembre de 1999). De entrada se puede identificar como un mapa técnico, elaborado a escala con referencia a las coordenadas oficiales de Colombia. Se trata de un mapa dibujado por un plotter, probablemente producido por un SIG — sistema de información georreferenciada-. El elemento central de este mapa es el área del "Bloque Samoré" una figura geométrica en forma de " $S$ " formada por líneas paralelas. Aparece en línea gruesa en el centro del plano superponiéndose, transparente, sobre lo demás. En la parte superior del bloque se muestra, dibujada en líneas puntadas, una retícula con una serie de puntos resaltados. Ni en las convenciones ni ninguna leyenda identifican el sentido de estas líneas. Se trata de los ejes trazados para la exploración sísmica. Bajo el Bloque Samoré aparecen, como piezas de un rompecabezas, las áreas de los parques y de la reserva y los resguardos, en tonos de gris. En gris más claro un área "de recuperación" y un "área recuperada”. Suponemos que se trata del área del "Resguardo Único" solicitado por los indígenas. El resto, en blanco. Aparecen la línea de la frontera con Venezuela y los límites departamentales entre Boyacá, Arauca y Norte Santander. Se muestra la vía que une las poblaciones de Saravena-Cubara-Samoré y se ubican algunas otras poblaciones cercanas a esta, todas en el área en blanco. La única población que aparece sobre el área coloreada es El Chuscal, donde se encuentra el internado de la misión. Esta aparece en el "área recuperada" sin que se muestre la carretera que conduce allá. No se hace ninguna referencia en el mapa a la Sierra Nevada ni a los límites de la zona montañosa con el llano. No aparecen los accidentes topográficos, lo cual es notorio puesto que la principal característica geográfica de la zona es su rápida ascensión del llano a las nieves perpetuas.

\section{2. 2. Mapa “Territorio U'WA"}

Este mapa fue preparado por AsoU'wa y aparece acompañando a varios de los documentos públicos de la organización, entre ellos dos de sus comunicados a la opinión pública (11). Es claro que este, aunque no sea un mapa "técnico" ni haya sido hecho a escala, sigue algunas de las convenciones de la cartografía occidental: se trata de una vista teórica desde encima, el norte hacia arriba y tiene una tabla de convenciones. Aparecen básicamente los mismos elementos que en el mapa anterior: el área del Bloque Samoré, los resguardos, el parque natural y el "área del territorio tradicional en recuperación", los ríos, la carretera y pueblos, sin embargo, el elemento central del mapa es la hidrografía. Aparecen con detalle los cauces de once ríos que bajan de la serranía y sus afluentes cada uno con su nombre. Las cumbres de la Sierra Nevada aparecen ubicadas por el nombre. Como un gran blanco en el centro del mapa el resguardo de Cobaría con un pequeño apéndice, la reserva. A los lados dos áreas en rayadas que denotan "territorios en recuperación" que se traslapan con el área del Bloque que aparece como un borde angosto punteado. Se destacan en estas dos últimas zonas una serie de óvalos con los nombres de 16 "comunidades". Aparecen otros dos resguardos que se traslapan con el Bloque: Angosturas y Curripao, ubicados hacia

(11) Ver por ejemplo la solicitud de creación del Resguardo Único U’wa presentada en 1993 al Incora, o el Manifiesto Público U'wa de junio de 1995. 
el sur. El parque nacional aparece ubicado como nombre, sin mostrar sus límites. Se muestran también los municipios de Chiscas y de Guicán los que se ubican al otro lado de la nevada. El ámbito geográfico que muestra este mapa es mucho más amplio que el anterior. Se puede decir que representa toda la vertiente nor-oriental de la Sierra.

\section{2. 3. Mapa “Territorio U'wa: Ancestral, Propuesto y Reconocido"}

Este mapa fue elaborado por Project Underground, del UDWG, y publicado en La sangre de nuestra madre (1998) donde el UDWG expone su lectura y el análisis del caso. Es también un mapa técnico, y al igual que el de la OXY, es un mapa de áreas. En negro aparece el área que corresponde al resguardo y a la reserva. A su alrededor, el área el Resguardo Único propuesto por AsoU'wa y el Bloque Samoré con las líneas de la sísmica de OXY. Se indica también el área de los dos parques, todo ello contenido en un área en blanco mucho mayor que representa "Kajka Ika: el Territorio Ancestral U'wa (incluye el bloque Samoré completo)", según reza la leyenda. Se ubica también el sitio propuesto para la perforación. En este mapa no aparece ningún punto que haga referencia ni a la topografía, ni a las vías, ni poblados, de manera que es difícil ubicar

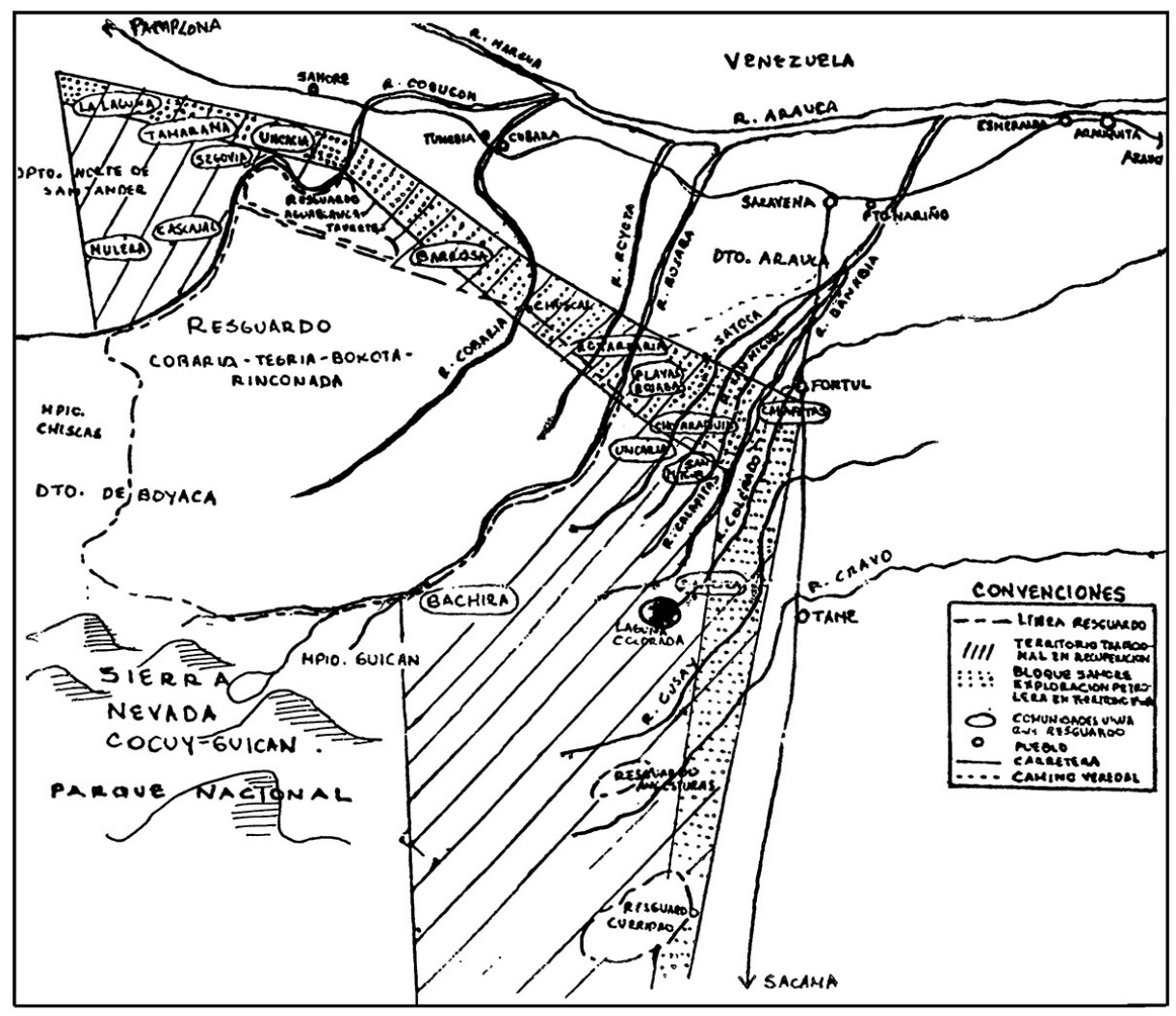

Fig. 3 - Mapa “Territorio U'WA" (elaborado por Asou'wa). 


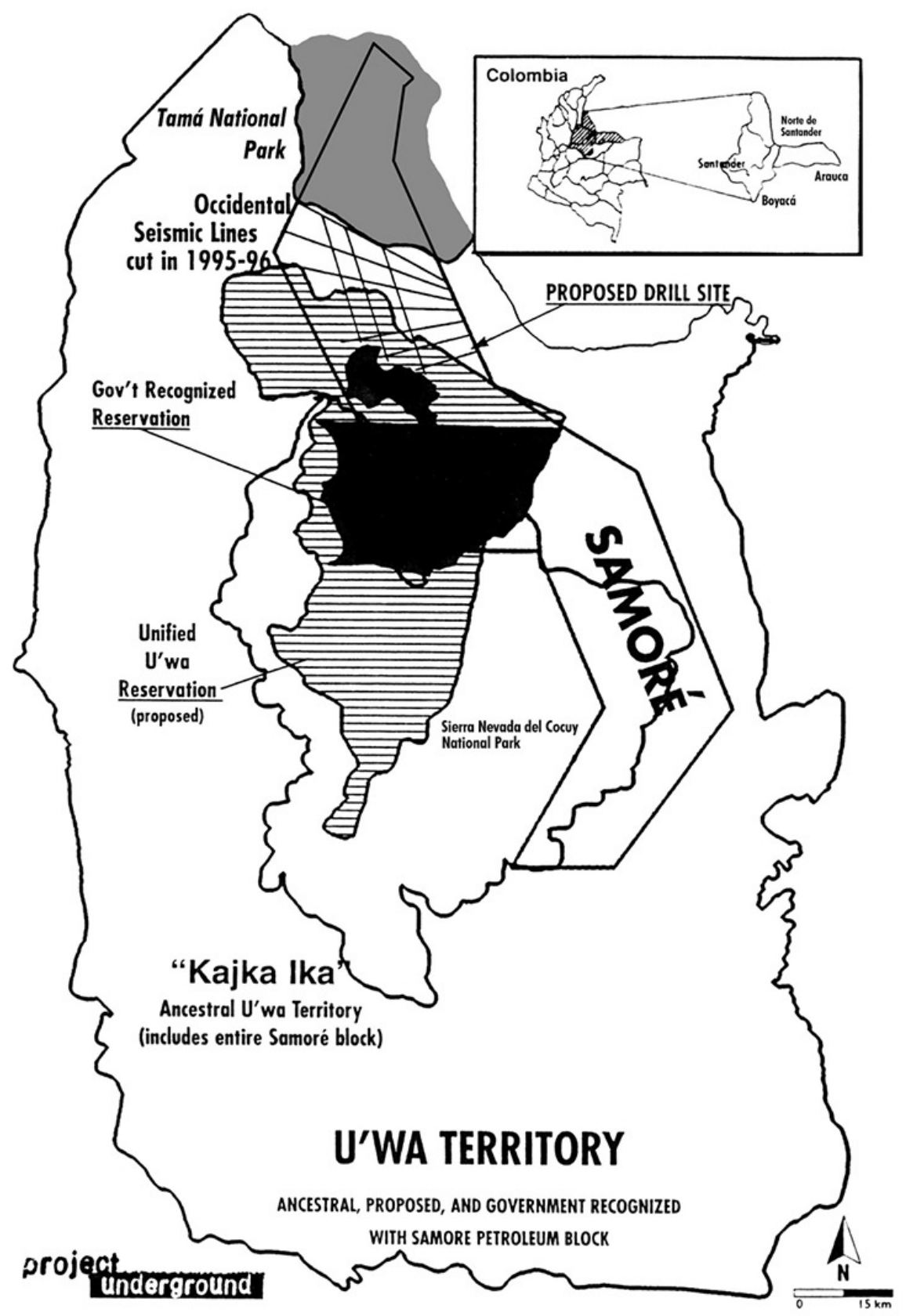

Fig. 4 - “Territorio U'wa: Ancestral, Propuesto y Reconocido". 
los referentes del "Territorio Ancestral". Aparentemente el ámbito geográfico de este, que es el mismo del mapa, abarca la totalidad de esta esquina de la cordillera y el piedemonte, entre los ríos Arauca y seguramente el Ariporo situado a unos $135 \mathrm{~km}$ al sur.

\section{3. La geografía de las ausencias}

Los tres mapas muestran de diferentes maneras el juego de las áreas en cuestión, lo que, al igual que la similitud de sus títulos, hace explicito que los tres se centran en delimitar el Territorio Indígena. Este, sin embargo, se ve representado de maneras completamente diferentes.

Los dos mapas técnicos tienen en común más de lo que podría esperarse que hubiera entre OXY y el UDWG. Para empezar, ambos omiten toda referencia a la Sierra Nevada, a su orografía y a su hidrografía. Un observador desprevenido, que desconozca la región, nunca podría imaginarse a partir de estos dos mapas, la abrupta topografía de la zona que asciende casi del nivel del mar a más de cinco mil metros en cerca de $50 \mathrm{~km}$. Al hacer abstracción del contexto geográfico, logran crear la impresión de que se trata de una zona neutra, no afectada por ningún tipo de accidente, ni de vegetación, ni de poblamiento, pues otra gran ausente en ambos mapas es la ocupación humana. El de OXY se limita a señalar las poblaciones mayores a lo largo de la vía, dejando el resto del área en blanco. Ninguno de los dos mapas muestra para nada la ocupación ni indígena, ni campesina de la zona, no aparecen poblados, ni caseríos, ni veredas, ni "comunidades". Con excepción del Chuscal en el mapa de OXY, ambos logran dar la impresión de que se trataría de un territorio despoblado o con un tipo de poblamiento tan poco establecido a sus ojos, que no llega a clasificar para aparecer en un mapa.

El mapa de AsoU'wa por el contrario, hace énfasis en la ocupación indígena del área en disputa. El centrar toda su representación del espacio en los cauces de los ríos es un claro ejemplo de ello. El hecho de que este pueblo tiene un tipo de poblamiento móvil, ha sido documentado ampliamente en la etnografía (Osborn, 1990; 1995; Marquez, 1981; Chavez, 1985). Las familias indígenas se desplazan a lo largo del año, de acuerdo al ciclo de las cuatro estaciones, entre los diferentes pisos térmicos, siempre a lo largo de una misma cuenca. El cauce de cada río es un distintivo de pertenencia central. El sistema de cuencas y micro cuencas es pues importante en la organización tanto social como espacial. Según Osborn (1995: 58): "los territorios de los distintos clanes coincidían con las cuencas de los grandes ríos de la zona". Cada comunidad se identifica por su pertenencia a una cuenca; esta es la que da el sentido espacial a la comunidad. Lo anterior se expresa claramente en el mapa siguiente, que aunque no hace parte de los mapas oficiales de la controversia, me parece importante traer como referencia a la discusión, con el fin de comprender mejor la representación cartográfica propuesta por AsoU'wa.

\section{3. 1. Mapa "Comunidad de Barrosa"}

Este mapa se encuentra, junto con otros similares, en la cartelera del salón de reuniones comunitarias en Casa Roja. Se trata de un mapa de Barrosa, una de las "comunidades" ubicadas en el área "en recuperación" que hace parte del bloque Samoré. 


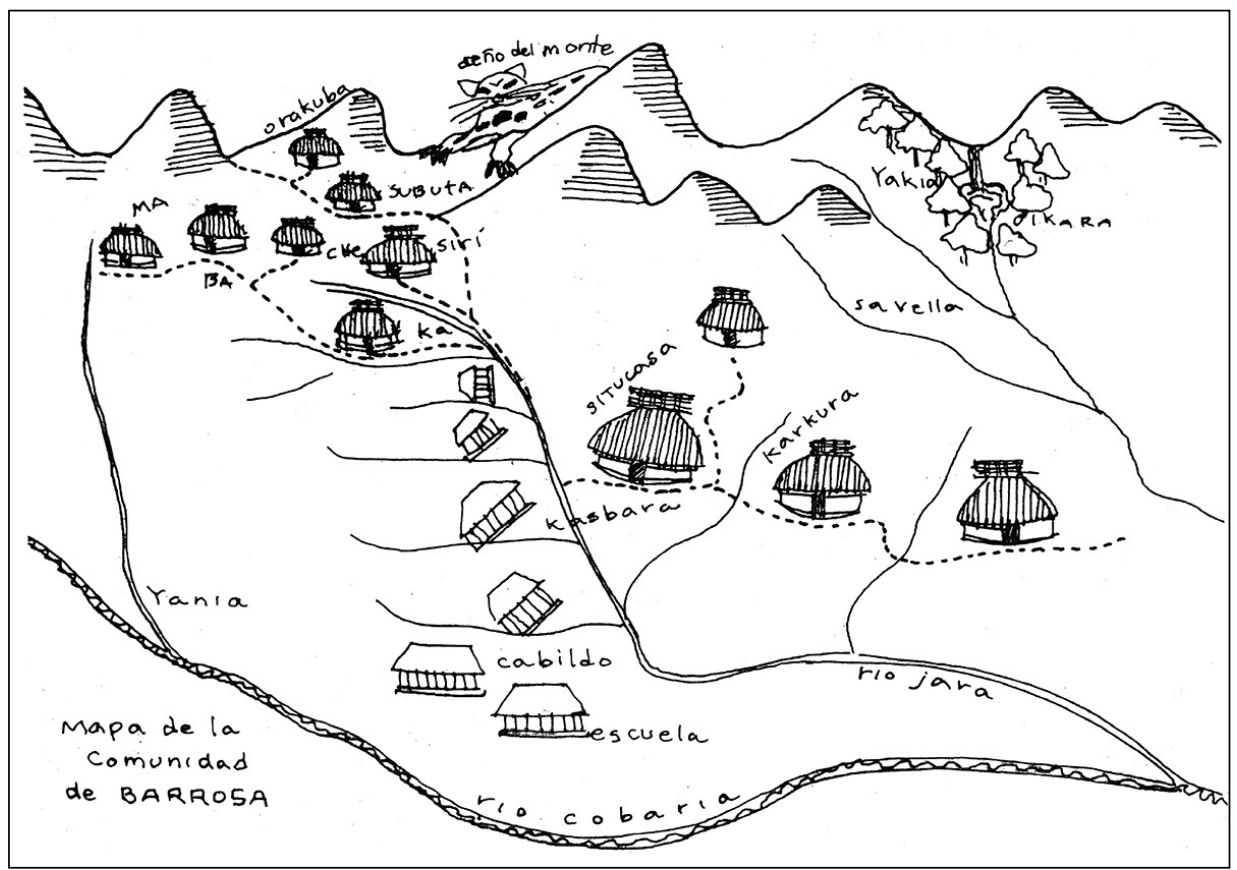

Fig. 5 - Mapa “Comunidad de Barrosa”.

Aunque este mapa no haga parte de ninguno de los documentos formales de AsoU'wa, se hizo una copia de este para entregar a las instituciones como parte de una serie de "diagramas" de las "comunidades", para que se tuvieran en cuenta en el estudio de tierras para la legalización del Resguardo Único. Este mapa fue preparado por la escuela de Barrosa, por el profesor, los alumnos y algunos padres de familia según me informaron. Muestra el río Jara, uno de los afluentes del Cobaría, con sus quebradas, en su recorrido desde el páramo. Señala el camino veredal en líneas punteadas y las casas. En el mapa hay una combinación de la vista en planta, en el recorrido de los ríos y caminos, con la perspectiva del "ojo de pájaro" con la que se ven las montañas y las casas. Aparecen dos tipos de casa, unas cuadradas como la de la escuela y el cabildo y otras con las cumbreras que se usan en los techos de las ubacha, las construcciones indígenas de la zona. Estas aparecen todas con nombres. Tuve la ocasión de hacer un recorrido por esa cuenca y pude entonces constatar que estas últimas representan pequeños asentamientos formados por un grupo de construcciones diversas entre las que se encuentran viviendas de varios tipos y cobertizos que pueden pertenecer a más de un grupo familiar. Hay también en la zona construcciones dispersas que no aparecen en el mapa. Las casas cuadradas corresponden a las construcciones que se han hecho en desarrollo de proyectos institucionales. Además de la escuela y la casa del cabildo, están el puesto de salud y las construcciones de un proyecto de desarrollo agropecuario, todas en franca decadencia. Sobre el perfil de las montañas se asoma el jaguar, o "dueño del monte". Se ve también una cascada muy alta que en el mapa se aparece rodeada de 
árboles. Es interesante que se destaque un grupo de árboles en una zona de bosques. En el paisaje U'wa predominan las selvas de montaña, con claros para las chagras y las construcciones. En la parte baja de la cuenca, acompañado los proyectos de desarrollo institucionales, se encuentran áreas de potreros.

Así, la comunidad de Barrosa tiene una identidad en tanto que ocupa la micro cuenca del Jara, pero hace también parte del territorio del clan de los Cobaría, que ocupa la cuenca del Río del mismo nombre. Por ello, el reconocimiento cartográfico de las cuencas es tan importante en el mapa de AsoU'wa. No es gratuito entonces el hecho de que la solicitud para la conformación del Resguardo Único se presente con referencia a las cuencas de los ríos. Y por ello, la ausencia de las cuencas en los mapas técnicos, que deciden hacer abstracción de los accidentes topográficos de la zona, son cruciales.

El área de los resguardos reconocidos legalmente aparece como un gran blanco en el mapa de AsoU'wa. El área en disputa, es decir la que corresponde al bloque Samoré, que se traslapa para los indígenas en su totalidad con el "territorio tradicional en recuperación", se muestra como un área profusamente poblada. Efectivamente, se destacan en el mapa la serie de óvalos con los nombres de las comunidades. Estas aparecen de manera contigua y equivalente, pues se ve una secuencia de óvalos, todos del mismo tamaño. Como lo ha mostrado el mapa de Barrosa (una de las que se representan por medio de óvalos en el área en recuperación), el referente de una comunidad no es un punto que pueda corresponder a un poblado o caserío. La "comunidad" se refiere a todo el sistema de ocupación de una micro cuenca. Los óvalos de este mapa corresponden entonces a este tipo de comunidades. Aparecen por ello, referenciados de manera diferente a los puntos con los que se representan los poblados ubicados a lo largo de la carretera.

Otro rasgo que comparten los dos mapas técnicos es el de mostrar la región como si ésta estuviera desarticulada de otras regiones del país como lugar lejano y, en últimas, como Tierra de Nadie, en la medida en que no muestran tampoco la manera en que se articula internamente. En el mapa de la UDWG aparece sólo la superposición de áreas ubicada de manera muy general en un mapa de Colombia, sin ningún otro tipo de referencia. El mapa de OXY muestra la carretera nacional, aunque de manera fragmentada y no se preocupa tampoco por referirla a sitios que puedan ser reconocidos más allá del ámbito local. Se trata del eje vial que une a Saravena con Pamplona y Arauca en sentido Occidente-Oriente y con Yopal-Villavicencio, o con Sácama y Tunja en sentido Norte-Sur. El mapa de AsoU'wa, en cambio, nos muestra claramente los dos ejes de la carretera, y por medio de flechas indica que hacia el oriente se llega a la ciudad de Pamplona, hacia el oriente a la de Arauca y hacia el sur a Sácama. Muestra, por otra parte, con líneas punteadas algunos caminos veredales que comunican la zona indígena en la montaña con el llano por donde pasa la carretera. El hecho de articularse físicamente con otras regiones y así con el país es coherente con la argumentación de AsoU'wa, en el sentido de que la autoridad indígena hace parte del Estado y de que se trata precisamente de lograr el reconocimiento de los derechos y prerrogativas que su pertenencia a este les confiere (12). Para la OXY y para el Estado, que han expresado en

(12) En Colombia las Autoridades Tradicionales y Cabildos están reconocidas constitucionalmente como entidades públicas de carácter especial con autonomía política y administrativa y se delega en ellas varias funciones estatales como la prestación de los servicios básicos de salud y la educación y funciones jurisdiccionales. Los resguardos tienen ademas status de entidades territoriales. 
repetidas ocasiones que los intereses de tres mil indios no pueden detener el desarrollo de un país, tiene más sentido mostrar esta región como un rescoldo del espacio y del tiempo. Es así como también el UDWG presenta a los indígenas: fuera del tiempo.

El efecto de invisibilizar el poblamiento indígena, se refuerza con el manejo que hacen los mapas de los topónimos. Mientras que el mapa de AsoU'wa enfatiza los nombres de los ríos y de sus afluentes y destaca la toponimia indígena, el mapa de UDWG, no toma en cuenta ningún rasgo ni topónimo local, se limita a titular las áreas destacando con las letras más grandes y gruesas el área del bloque Samoré. El mapa de OXY privilegia los nombres de las divisiones jurídico-administrativas, los parques y las poblaciones más grandes sobre la vía, pone los nombres del resguardo y la reserva en letra pequeña y no aparecen ni los nombres de los ríos ni de ninguna localidad indígena con excepción del Chuscal.

Los grandes ausentes en toda la cartografía, y en realidad en la polémica en general, son los campesinos. La población campesina en la zona es numerosa, se trata en su mayoría de colonos provenientes de distintas partes del país, llegados en su mayor parte, durante los años sesenta. Con los proyectos de colonización dirigida surgieron los municipios de Cubará y Saravena y se consolidaron diversos corregimientos y veredas (precisamente ausentes en los mapas como Fátima, Campo Alicia, Las Delicias, Cúcuta, San Joaquín, Laguna, Morretón, El Mesón, El Silencio y otras). Solamente en el área reclamada por los indígenas para el resguardo único habita hoy una población de cerca de dos mil campesinos ( $c f$. U. Javeriana, op.cit.). Una de las actividades que implica para el Estado el reconocimiento jurídico del resguardo único es la de comprar los títulos de propiedad que le fueron otorgados a familias campesinas dentro de las tierras reclamadas por los indígenas, implica ademas comprar las “mejoras". Los colonos son invisibles no sólo en los mapas sino en toda la argumentación de la controversia, pues si bien la ley colombiana contempla para los indígenas el derecho a ser consultados sobre las actividades y proyectos a realizar, este no se le reconoce a los campesinos.

\section{4. La naturaleza de los mapas}

De cierta manera los mapas públicos de la controversia pueden ser vistos como ejemplo de lo que Monmonier (1993: 142) denomina "el efecto de propaganda", que se presenta cuando los mapas pretenden aumentar la importancia de un país o de una región, o en este caso, de un área, o al contrario de hacerla aparecer pequeña y amenazada. Para ello modulan el mensaje del mapa, acentuando los detalles que se conforman al punto de vista que se quieren imponer. En este sentido, cada uno de los mapas propuestos en la controversia nos muestra de manera distinta al bloque Samoré: el mapa de AsoU'wa muestra el bloque totalmente ocupado por las comunidades y cruzando por el medio su territorio. En el mapa de OXY aparece neutral y transparente y muestra las actividades sísmicas en un área aparentemente no reclamada. El mapa del UDWG destaca el bloque y lo superpone como una intrusión total al territorio ancestral.

Tal vez la diferencia más impactante entre los dos mapas técnicos y el mapa de los indígenas es finalmente que el rasgo en el que se centran tanto UDWG como la OXY es en el juego de áreas, es decir lo que nos muestran ambos son una serie de líneas 
imaginarias. Con este conjunto de líneas se dibuja el perímetro inmaterial de una serie de áreas nítidas, aparentemente uniformes, homogéneas y regulares. El mapa indígena se centra en cambio en la representación de una serie de elementos de los que se tiene experiencia directa, como los ríos, las lagunas, las comunidades, la carretera. En el mapa de AsoU'wa las entidades político-administrativas, incluyendo los parques naturales, aparecen como nombre, sin límites precisos, mostrando así seguramente que se trata de una autoridad que se reconoce pero cuya presencia no hace en realidad parte de la experiencia. Tal vez aquí se expresa realmente el sentido que tiene la argumentación para las partes. Lo que está en juego en últimas, para los indígenas, es la práctica de la cotidianidad, el sentido de su experiencia concreta. Para la OXY y para el Estado, así como para el grupo de ONGs, en cambio lo que está en juego es un Orden teórico: así lo muestra el hecho de que su argumentación está formulada en términos utópicos (13), es decir en términos de un orden y una racionalidad con las que se busca regular las actividades sociales para que coincidan con las líneas que enmarcan unas áreas. El sentido de la argumentación de los unos se construye en base a las circunstancias actuales de su vida cotidiana y el sentido de la de los otros, en base a un supuesto Deber Ser.

El hecho de que los mapas técnicos se reduzcan a mostrar el juego de áreas, como si fueran un rompecabezas es expresión de la concepción moderna del ordenamiento territorial. Hace parte de la concepción de que la vida de una región (o de una ciudad, o de una casa) se comprende para fines de planificación en términos de un número limitado de funciones (v.gr. sitios de habitación, circulación, producción agraria, etc.) que deben ser organizadas como áreas mutuamente excluyentes. Así, el ordenamiento del territorio se centra en el ejercicio de la zonificación. Es claro que la respuesta a la disputa, como lo entienden tanto el Estado como las compañías petroleras, está precisamente en encontrar una respuesta de tipo zonal, como el caso de los parques naturales. De esta forma, la explotación petrolera representa solamente un problema de geometría, de restar áreas. Se trata de encontrar un área para ubicar las perforaciones que no se traslape con las áreas reconocidas legalmente a los indígenas, de la misma forma en que no pueden superponerse tampoco a los parques nacionales. Como si las actividades y procesos que conlleva cualquier tipo de intervención social pudieran ser contenidas dentro de los límites de una zona. De hecho, fue esta la respuesta que dio el Estado al reconocer jurídicamente el "Territorio Unido U'wa", mediante la resolución 056 de Agosto de 1999 (Ministerio del Ambiente). Este hecho queda explícito en un mapa publicado en el diario El Espectador acompañando el artículo Guerrilla y ONG utilizan a los U'wa el 10 de abril del 2000). Se titula La exploración y los U'wa. Ya no aparece el bloque Samoré. La silueta central es la del Resguardo Unido U'wa, en su

(13) En la Utopía de Thomas More publicada en 1616 se ven plasmadas las pautas del pensamiento que va caracterizar y sustentar la ideología del progreso y la modernización: a partir de una serie de mitos fundadores, y a nombre de unos ideales éticos — los del judeocristianismoy estéticos — los de la cultura racional moderna-, supuestamente universales, se prescribe un orden institucional y espacial. La premisa de que la existencia de este orden físico e institucional garantizaría por sí mismo la armonía social, parte de los mismos supuestos en los que se funda el determinismo ambiental. Las formulaciones utópicas suponen que un cierto tipo de ambiente pueden definir el comportamiento y la sensibilidad de la gente. Para una visión panorámica sobre la Utopía y el pensamiento utópico ver p.e. Borsi, 1997; Manuel \& Manuel, 1979; Georges, 1994. 
interior la silueta del resguardo y la reserva anterior. Por el borde superior externo del resguardo unido pasa una línea gruesa, en negro, que representa el oleoducto Caño-Limón Coveñas y finalmente un cuadradito muy pequeño muestra el área del pozo Gibraltar. La leyenda dice: resguardo unido: 220275 hectáreas, resguardo y reserva anteriores: 65156 hectáreas y área de influencia directa del pozo propuesto: 449 hectáreas. El mapa muestra la relación matemática de áreas. Allí queda dicho todo.

La narrativa de la planificación técnica se sustenta precisamente en el análisis objetivo que se puede llevar a cabo apoyándose en los mapas técnicos, a través de un método lógico, que permite evaluar las localizaciones posibles de la explotación. A través de este tipo de mapas se está diciendo al público "tranquilos que nosotros sabemos lo que hacemos, no lo estamos haciendo al azar, no se va a improvisar pues, como pueden ver en este mapa, nos respalda un arsenal poderoso de tecnología que garantiza nuestros resultados". Al mismo tiempo muestran la ubicación del bloque petrolero como una actividad económica neutral, como una actividad benéfica, que no responde a ningún tipo de propósitos políticos ni está inmersa en relaciones de poder.

Por su parte, el mapa que propone la UDWG, reproduce, paradójicamente, el carácter no problemático, casi que higiénico, con que la OXY busca mostrar el bloque Samoré: un área producto de una acción racional y ordenada. Esta imagen nítida de un área homogénea, atravesada sólo por la retícula ortogonal de las líneas de la exploración sísmica, es una cortina de humo detrás de la cual se ocultan los hechos espaciales que implicarían tanto la exploración como la explotación: las carreteras que habría que construir, los campamentos y asentamientos que se hacen necesarios, el incremento en el tráfico de las vías y en las poblaciones existentes, los puestos de control y vigilancia, la ubicación de nuevas unidades del ejercito, por mencionar sólo algunos.

La UDWG al centrar su mapa en el área de un Territorio Ancestral que lo abarca todo, recurre a la autoridad del relato escencial de "Kajka Ika". Hay en este tipo de argumento una relación con la lógica conservacionista de preservar intactas las zonas que se consideran prístinas y al centrar el mapa en este tipo de argumentos, se termina por reificar la cultura indígena. Evade otros temas que se podrían abordar como, por ejemplo, la complejidad del manejo vertical de la sierra por parte de los indígenas el que no solamente es importante desde el punto de vista del acervo tecnológico que representa, sino que de este depende la supervivencia de los bosques tropicales de montaña que cubren hoy casi toda la región. Estas selvas son parte del paisaje que producen los U'wa, y constituyen uno de los ecosistemas en mayor peligro de extinción en el planeta, según The World Conservation Monitoring Centre (WCMC) (1995). A esta serie de aspectos no se refiere nadie, curiosamente, en el marco de la controversia, como si fueran una realidad aparte y separada de la forma de habitar la Sierra Nevada por parte de los U'wa. "Conservar la Naturaleza” es una función que se adelanta al decretar la zona del "Parque Natural" como área que va a ser teóricamente mantenida intacta.

Mientras que la legitimidad de los mapas técnicos radica en este carácter neutral y en la supuesta objetividad y exactitud con la que ubican espacialmente sus referentes, la legitimidad que el mapa de AsoU'wa reclama, radica en la manera en que expresa su apropiación del territorio. No solamente la exposición detallada de 
las cuencas hace parte de ello, sino el hecho de señalar y nombrar las comunidades, así como mostrar las cumbres y lagunas. Se trata de sitios que, como el "dueño del monte" en el mapa de Barrosa, tienen una significación particular que denota su ocupación. El conjunto de elementos del paisaje que destacan los mapas indígenas se puede leer como una serie de "pistas" escondidas en la urdimbre de la representación cartográfica, que evocan una manera particular de imaginar y por lo tanto de "ocupar" el espacio. Los U'wa viven una realidad definida por categorías y leyes particulares que se expresan en una serie de "mitos cantados" (14). En estos relatos se enuncian, se recrean y se interpretan, mediante su celebración, las leyes y los principios que rigen el mundo en que viven. A través de las historias y situaciones que evocan y de la manera de cantarlas y celebrarlas, se organizan las actividades básicas de la vida cotidiana. En estos cantos se relaciona el pasado, el presente y el futuro, se definen los conceptos básicos del tiempo y del espacio y se da cuenta de la naturaleza de las cosas en el mundo. La enunciación o canto de estos relatos enmarca todo aquello que puede ser posible en el mundo U'wa.

En el principio el universo U'wa comprendía dos esferas: un mundo de arriba, seco, luminoso y con fuego y un mundo de abajo, oscuro, húmedo y vacío. Estos dos mundos eran estáticos, estaban separados, delimitados y eran opuestos y absolutos. Después hubo movimiento y los mundos de arriba y de abajo se encontraron, se intersectaron. De su mezcla surgió el mundo del medio, en el que vivimos.

Los mundos están identificados y asociados con colores. El mundo de arriba se asocia al Blanco y al mundo de abajo se asocia al Rojo. Cuando se mezclan surgen Azul y Amarillo. Así como el universo, en general el espacio está constituido por dos ámbitos opuestos e invertidos. La tierra donde vivimos se asocia con el Azul y está compuesta por dos mitades, cada mitad se concibe como una casa. De igual manera, los menhires que hay dispersos en el territorio U'wa son postes de vivienda que unen las dos mitades de Azul y por extensión todo el universo (Osborn, 1995: 74). A su vez, Rojo y Blanco al igual que Azul parecen estar conformados por dos mitades opuestas y sus habitantes ya sean estáticos o móviles, están designados según se encuentren ubicados Arriba o Abajo en sus respectivos mundos (Osborn, 1995: 76).

Las condiciones y las propiedades que caracterizan los mundos y espacios son también opuestas e invertidas. El de arriba, es seco, masculino, frío e infértil, y el de abajo es húmedo, femenino, caliente y fértil. Estas inversiones se proyectan sobre el territorio U'wa. Las tierras altas y el páramo son Arriba, el lugar de las nieves blancas y perpetuas y del frío. La llanuras, Abajo, se consideran rojas y calientes. Las actividades

(14) A partir de los trabajos etnográficos de Ann Osborn que son, por lo demás, referencia constante en la argumentación del caso. La representación de los U'wa que hace Ann Osborn es bastante compleja por lo que estas no pasan de ser, la mayor parte de las veces, meras reducciones de sus planteamientos. De sus diez trabajos publicados sobre los U'wa, el que se cita casi exclusivamente es su tesis doctoral para la Universidad de Oxford: Las Cuatro Estaciones: Mitología y estructura social entre los U'wa, Se trata de un estudio sobre la estructura del mundo simbólico, a través de la mitología, escrito en términos académicos, denso, no propiamente dirigido a un público amplio. La visión de este pueblo indígena elaborada por ella, nos asoma a un mundo complejo y profundo. Logra, sobretodo, transmitirnos la capacidad de maravillar que ha constituido siempre, parafraseando a Malinowski, "la magia de la etnografía". 
que se desarrollan en estas zonas también están invertidas. Sin embargo, se considera que al estar en el centro, en el pie de monte y en las faldas de la serranía, los U'wa separan y limitan los dos mundos. Pero a la vez, por haber surgido de la mezcla de los extremos, viven en condiciones de mezcla y tienen propiedades de ambos (Osborn, 1995: 243).

Este principio de estructuración del mundo, el de la inversión de opuestos, no es una dualidad comparable a la del sistema de oposiciones heredada del pensamiento griego. Para los U'wa el mundo real no se compone de opuestos invertidos sino del producto del movimiento y la transformación, es decir del producto de la conjunción, la amalgama y la fusión de estos opuestos. En el pensamiento $U$ 'wa muchas situaciones y procesos suelen tener tres posiciones posibles: las dos oposiciones contrastantes derivadas de los mundos extremos y otra derivada de su conjunción. La condición de perturbación del mundo del medio no parece ser un fenómeno de tipo marginal, sino que representa un estado importante para el desenvolvimiento del universo. Por esta razón, cuando se pregunta a que categoría pertenece algo es frecuente no obtener una respuesta clara, pues su naturaleza es mezclada. El hablar de pares opuestos en términos absolutos equivaldría para los U'wa a hablar de condiciones anteriores a la creación que ya no existen (Osborn, 1995: 74).

Si las mezclas (entre mundos, entre seres, entre entidades) no tiene balance y lo que hace es agregar propiedades o características semejantes, se produce entonces un exceso que da lugar a condiciones extremas. La gente está siempre tratando de armonizar las conjunciones y los encuentros de propiedades que se dan en distintos niveles en la vida diaria. El balance entre propiedades no es el estado natural ni de las cosas ni de las circunstancias y se requieren importantes esfuerzos para lograrlo. Al juntar propiedades opuestas se producen mezclas y por lo tanto transformaciones. En el mundo U'wa todos los seres están sujetos permanentemente a un sistema de transformaciones que dependen de la mezcla de las propiedades entre opuestos.

Para los U'wa todos los seres estamos compuestos de ciertos elementos. Todas las cosas que crecen: las plantas, los animales y los humanos tienen cuerpo y "alma". Además todo tiene un componente indestructible: bita, una materia básica original, asociada con propiedades de inmortalidad, se refiere al cuerpo y a las cualidades inalterables heredadas (en oposición al alma). Sus características unificadoras ligan a todas las criaturas del universo (Osborn, 1995: 219). Las mezclas y, por lo tanto, las transformaciones de mayor importancia son las que pueden producirse en relación con las propiedades de lo que se consume. Se considera por ello que las cosas se transforman en lo que comen (Osborn, 1998). Los alimentos, incluyendo los alucinógenos, no solamente pueden pertenecer a diferentes zonas o esferas (Osborn, 1990: 30), sino que existe un conjunto de alimentos que contienen gran cantidad de la sustancia opuesta a la bita, a sus propiedades de inmortalidad. Las casas deben "cerrarse" a este tipo de alimentos así como a las gentes, indígenas y no indígenas que viven en otras casas, en otros mundos. Esta característica de encerramiento, de protección frente al contagio de propiedades, así como las reglas de introducción, cocción y uso de alimentos se relaciona pues, con el concepto de la casa como modelo, como representación del universo. Los objetos y seres traídos de fuera, de otros mundos tienen por ello que ser soplados, sometidos a un proceso de purificación que en el caso de las personas incluye periodos de ayuno, antes de entrar (Osborn, 1995: 153). 
Hay también una serie de transformaciones que se producen al desplazarse en el espacio o en el universo: un ser que tiene una forma en este mundo cambia su forma al pasar a otro mundo. En ello incide la dirección del movimiento, el sentido de los desplazamientos entre mundos y en el espacio. Por ejemplo, con la adquisición de los alucinógenos, los mamíferos del mundo intermedio pueden volverse pájaros en el mundo de arriba y los pájaros de este mundo se pueden volver shamanes en el mundo de arriba. Hay también transformaciones de tipo sexual. Es posible que los hombres se conviertan en carnívoros hembra, y que los carnívoros machos al volverse gente se convierten en mujeres (Osborn, 1995: 218). En la transformación de los shamanes a carnívoros, se hace énfasis en el poder visionario del alucinógeno: este hace cambiar de visión. De acuerdo al lugar y a la transformación, el shaman se ve a sí mismo como jaguar, oso o pájaro según viaje al mundo de abajo o de arriba y estos animales se ven a su vez a sí mismos como gente en sus respectivos mundos (Osborn, 1990:30).

Los U'wa, no hacen una distinción entre ellos y la naturaleza, todas las cosas vivas incluyendo las plantas son vistas como mortales, que tienen los mismos componentes y fuentes de vida y están por lo tanto relacionados (Osborn, 1990: 40). La distinción que hacen con "otros" se basa entonces en el hecho de no compartir la celebración de los cantos, y por lo tanto de no comprenderlos ni saber interpretarlos (Osborn, 1988: 28). En esa medida los “otros" para los U'wa son quienes desconocen el complejo de esencias y propiedades especificas de los mundos, el que se expresa particularmente en la alimentación. Por ello es usual, que se establezcan fronteras con base en la comida. (Osborn, 1988: 38). El "Dueño del Monte" asomado tras los filos de las montañas en el mapa de Barrosa es la cima del iceberg de todo este mundo, invisible en la confrontación. Aunque la concepción espacial del pensamiento U'wa vea, de hecho, reducida su multi-dimensionalidad y su multi-referencialidad en la representación plana, bidimensional del mapa; logra sin embargo expresar su relación particular con el Cosmos en la referencia a los sitios evocados por los mitos cantados: los ríos, las cumbres y las lagunas y los nombres de los clanes.

Las visiones que proponen los mapas no son sin embargo del todo inconmensurables. Hay un punto de partida importante en el hecho de que todos se reconocen mínimamente: ninguno de los autores de los mapas borra del todo a los otros, aunque los represente de forma que su presencia no diminuya la soberanía que reclama sobre el área. Por otra parte, el hecho de que los mapas hacen referencia de un modo u otro al "territorio tradicional", expresa claramente el énfasis que se le ha dado a la disputa: todos los actores han privilegiado una visión de la controversia como conflicto étnico. Dicho en otras palabras, un conflicto en el que están en juego una serie de reivindicaciones políticas cuya legitimidad radica en el hecho de ser propuestas por un grupo social que se reconoce en tanto que grupo étnico. El hacer énfasis en esta dimensión del conflicto y reducir las diferencias culturales a una posición estratégica para "negociar" tiene una serie de implicaciones de las que voy a destacar aquí algunos aspectos.

La cultura, en este marco, tiende a verse como sinónimo de etnicidad y de identidad étnica. La etnicidad se refiere, en términos generales, a la categorización de las personas en función de su supuesto origen que se legitima a través del despliegue 
de signos culturales socialmente diferenciados. Designa la manera en que los actores sociales formulan las divisiones y desigualdades en términos de pertenencia y de diferenciación étnicas. Las diferencias culturales terminan en esta conceptualización por verse reducidas a una serie de comportamientos (usos, valores y costumbres) tradicionales y estereotipados, supuestamente distribuidos de manera homogénea entre todos los miembros de un grupo, con base en los cuales se establecen fronteras "culturales". La planificación y las prescripciones del desarrollo han privilegiado precisamente esta forma esencialista de entender la cultura. Han terminado por confundirla con la serie de rasgos - muchos de tipo esencial - a partir de los cuales se construye el discurso estratégico. El énfasis en lo étnico nos muestra una visión romántica, estática y banal de los U'wa como guardianes de la madre naturaleza.

La fachada de etnicidad invisibiliza el hecho de que están de por medio dos maneras diferentes de entender la naturaleza y la naturaleza de la realidad — es decir, dos aproximaciones epistemológicas al cosmos - y no meramente una pugna por el acceso a la satisfacción de las necesidades supuestamente universales que conlleva la "occidentalización". El que el concebir la confrontación en estos términos resulte estratégico para las partes, no implica que su dimensión cultural pueda verse reducida a ella.

En la cartografía se expresa claramente el hecho de que tanto el Estado como las Compañías y el UDWG comparten la visión moderna de la naturaleza como una realidad material, objetiva y mesurable, externa a lo humano. De acuerdo con Williams (1976), esta cualidad objetiva y mesurable del mundo natural se entiende también como cualidad esencial del mundo real. Esta forma particular de concebir la naturaleza, en la que se ve en últimas reducida a los conceptos de "sistema" y de "recursos", es como el toque del Rey Midas, pues todo lo que va rozando se convierte en oro, es decir en valor de cambio. Como lo resume Oelschlaeger (1991: 94) "a través de la alquimia económica, la naturaleza salvaje - los ríos y los bosques, las plantas y los animales - se ha visto transformada en recursos materiales: materia-en-movimiento: un medio para algún otro fin... vemos la naturaleza solamente a través de los ojos del Homo oeconomicus". Visión que contradice y difiere profundamente de la visión U'wa de la realidad donde la naturaleza no es concebida como algo externo al ámbito humano. Donde los seres humanos y no humanos, se categorizan de acuerdo con una serie de propiedades que comparten, relacionadas con los mundos o dominios donde se sitúan y donde una acción o evento en cualquiera de estos dominios o mundos va a ejercer una influencia en los otros: un movimiento, un cambio o una transformación.

El ver la disputa como un conflicto étnico no sólo contribuye a impedir el reconocimiento de otra manera de entender la relación entre lo humano y lo no humano sino que logra ratificar la impresión de que la forma occidental de imaginar la naturaleza es universal y de que es la única válida, y la única que puede brindar las herramientas (legítimas por ser "objetivas") para "manejarla". De esta manera logra también ocultar los supuestos de los que parte y los contextos históricos de los que surge impidiendo así ser reconocida como uno de los dispositivos más poderosos de imposición de la ecuación cultural inherente al proyecto económico racional moderno: (ciencia y tecnología + instituciones y modelos económicos racionales $=$ riqueza y consumo $=$ paz, bienestar y felicidad) 
Además, como lo subraya Descola (1998-1999) una de las consecuencias paradójicas de partir de la distinción occidental entre el mundo natural y el mundo social es que esta posición epistemológica impide una comprensión de los ecosistemas y rara vez permite ver los dispositivos sociales y su papel en la dinámica de estos, impidiendo la comprensión de la evolución de la sociedad en relación con la del ambiente. De hecho, sociedades como la U'wa, u otras como la tukano, la kogui, por poner algunos ejemplos no "conservan" la naturaleza con la que conviven, sino que en su interacción, la producen: el paisaje cultural que configuran y en el que habitan los yukuna o los achuar en la Amazonia es la "selva". La etnología y la arqueología han ilustrado ampliamante el proceso de producción del paisaje de bosques en la Amazonía (Van der Hammen, 1992; Politis, 1997). Las selvas no son "áreas naturales", prístinas, sino el producto social de las sociedades que conviven con ellas. El hábitat y el paisaje de cada sociedad no son únicamente producto de la "oferta natural" de los suelos, el clima y la altitud, también son producto de un conjunto de dispositivos sociales a través de los cuales algunas especies se valoran y que se reproducen, se seleccionan y se preservan y otras resultan desfavorecidas. Toda esta dimensión queda entonces por fuera de la discusión. Desde este punto de vista resulta particularmente interesante el hecho de que el Estado decida "conservar" el área de los parques, prohibiendo allí toda intervención petrolera. Se hace evidente aquí la concepción según la cual la naturaleza sólo es natural cuando es prístina e intacta, por lo que conservarla implica mantenerla así. Se hace evidente también que este tipo de conceptualización no es neutral ni inocente, pues implica ignorar totalmente la relación entre la sociedad U'wa con su entorno y sobretodo subordinar su existencia a unos intereses económicos exóticos.

Indudablemente la imposición de la verdad occidental se expresa en el papel que juega la autoridad de la ciencia y de la técnica en la controversia, expresadas en los argumentos de la planificación y el ordenamiento territorial. Nelkin (1989) ha mostrado cómo el saber científico se ha convertido en un recurso político al que se recurre como fuente de racionalidad y como base de legitimidad para cualquier tipo de decisiones. De esta manera es interesante notar como todos los actores recurren a la autoridad de la ciencia para justificar sus puntos de vista, para crear legitimidad. Termina éste por ser uno de los medios más poderosos de garantizar el control de los términos del debate por parte del Estado, quien es garante de la modernización que se adelanta en nombre de la ciencia y la técnica. Al definir la Ciencia como una fuente de autoridad universal se desplaza el encuentro intercultural, el encuentro entre visiones diferentes de la naturaleza de la realidad, a un lugar marginal en la controversia. Al dar por hecho que la visión científica es la fuente de legitimidad se da por hecho que hay una serie de aspectos que son totalmente irrelevantes: los que llevan implícitos la formas de vida y de pensamiento indígenas. Facilita el hecho de plantear que las formas en las que se puede desenvolver la disputa deben seguir la misma lógica con la que se gestionan los conflictos occidentales. Hace además incuestionable el hecho de que las posibles soluciones al conflicto se pueden dar únicamente en los términos que visualiza una cultura, es decir en términos de los "intereses" concebibles en el marco de las Normas y Derechos occidentales.

La autoridad de la Ciencia y de la Técnica enmascara el carácter epistémico de la disputa, término con el que MacMullin (1989) caracteriza las controversias que 
tienen por objeto la confrontación de proposiciones y teorías que se pueden enmarcar en paradigmas diferentes, la que sería una manera más aproximada de expresar lo que implican las diferencias culturales es decir las diferentes formas de entender la naturaleza y la naturaleza de las cosas. Se transforma en un poderoso mecanismo de poder, que no sólo logra negar y excluir otra sociedad y sus formas de vida social, sino que la obliga a encerrarse tras una máscara de esencialismos que la amordaza y la banaliza.

\section{Referencias citadas}

BORSI, F., 1997 - Architecture et Utopie, 197p.; Paris : Hazan.

CASTRO CAICEDO, G., 1972 - Colonos Embotellados. El Tiempo, 20 de febrero de 1972.

CASTRO CAICEDO, G., 1972 - El Sarare en Pié. El Tiempo, 22 de febrero de 1972.

CHAVEZ, A., 1985 - Reseña Etnográfica de los Cobarías, 150p.; Pamplona: Instituto de Bellas Artes de Norte de Santander - Casa Colonial de Pamplona.

CLIFFORD, J., 1976 - Identity in the Mashpee. In: The Predicament of Culture: Twentieth century ethnography, literature and art, 381p.; Cambridge: Cambridge University Press.

DESCOLA, P., 1998-1999 - Anthropologie de la Nature, Séminaire à l'EHESS, Paris.

EL ESPECTADOR, 2000 - Guerrilla y ONG utilizan a los U'wa, 10 de abril del 2000.

ELLINGSON, T., 2001 - The Myth of the Noble Savage, 445p.; Berkeley: University of Californa Press.

EL TIEMPO, 1997 - La guerrilla nos Acorrala: Oxy, 21 de abril de 1997.

EL TIEMPO, 1997 - La guerrilla ronda, 11; 2 de febrero de 1997.

EL TIEMPO, 1998 - Éxodo a Tame por Combates, 15 de diciembre de 1998.

EL TIEMPO, 1998 - OEA frena a la OXY en contrato Samoré, 22 de septiembre de 1998.

EL TIEMPO, 1998 - Oleoductos en la Mira de las FARC, 22 de junio de 1998.

EL TIEMPO, 1998 - Oxy no tocará territorio U’wa, 25 de mayo de 1998.

EL TIEMPO, 1998 - Sarare: tres décadas de olvido, 12 de agosto de 1998.

EL TIEMPO, 1998 - Utilizada ayuda militar de EEUU, 22 de diciembre de 1998.

EL TIEMPO, 2001 - De 'Arauca Saudita' a 'Ar-AUC-a'?, 3 de junio de 2001.

GEORGES, J., 1994 - Voyages en Utopie; Paris: Découvertes Gallimard.

HARLEY, J. B., 1989 - Deconstructing the Map. Cartographica, Vol.26, No 2: 1-20.

IDEADE, 1996-Estudio Socio Ambiental, Jurídico y de Tenencia de la Tierra para la constitución del Resguardo Único U’wa, 256p.; Bogotá: Universidad Javeriana.

LATOUR, B. \& WOOLGAR, S., 1988-La vie de laboratoire: la production desfaits scientifiques, 296p.; Paris : La Decouverte.

MACMULLIN, 1989-Science Controversy and its Termination In: Science Controversies: Case studies in the resolution and closure of disputes in science and technology (Englehardt y Caplan eds.): 49-91; Cambridge: Cambridge University Press. 
MANUEL, F. \& MANUEL, F., 1979 - Utopian Thought in the Western World, 896p.; Cambridge University Press.

MARQUEZ, M.E., 1981 - Los indios tunebos y su cosmogonía, 270p.; Caracas: Instituto de Investigaciones Históricas de Venezuela.

MITCHELL, W.J.T., 1986 - Iconology: Image, Text, Ideology, 226p.; Chicago: The University of Chicago Press.

MONMONIER, M., 1993 - Comment faire mentir les cartes; 232p.; Paris: Flammarion.

NELKIN, 1989 - Controversies and the authority of science. In: Science Controversies: Case studies in the resolution and closure of disputes in science and technology, (H.J. Englehardt y A. Caplan eds.): 283-293; Cambridge University Press.

OELSCHLAEGER, 1991 - The Idea of Wildernass, 477p.; New Haven: Yale University Press.

OSBORNE, A., 1988 - El Multiculturalismo en los Andes Colombianos. Revista Colombiana de Antropología, No 4(2): 25-42; Bogotá.

OSBORNE, A., 1990 - Comer y ser comido: los animales en la tradición oral U'wa. Boletín del Museo del Oro, No 26: 12-14; Bogotá: Banco de la República.

OSBORNE, A., 1995 - Las Cuatro Estaciones: mitología y estgructura social entre los U'wa, 269p.; Bogotá: FIAN - Banco de la República.

POLITIS, G., 1997 - Los Nukak, 426p.; Bogotá: ICANH.

RUCINQUE, H., 1972 - Colonization of the Sarare Region of Eastern Colombia. MSc. Thesis, Department of Geography, University of Wisconsin at Madison, 182p.

SCOTT, J. C., 1998 - Seeing like a State: How certain schemes to improve the human condition have failed, 445p.; New Haven and London:Yale University Press.

SOUSA SANTOS, B. de \& GARCÍA, M., (eds.) 2001 - El Caleidoscopio de las Justicias en Colombia, 2 vols: 546p.; Bogotá: ICANH-Uniandes.

VAN DER HAMMEN, M.C., 1992 - El manejo del mundo: naturaleza y sociedad entre los Yukuna de la Amazonia Colombiana, 376p.; Bogotá: Tropenbos y Tercer Mundo editores.

WORLD CONSERVATION MONITORING CENTRE, 1995 - Global Biodiversity: Satus of the Earth's living resources, 286p.; London: Chapman \& Hall.

WILLIAMS, 1976 - Key Words: A vocabulary of culture and society, 286p.; Oxford: Oxford University Press. 